\title{
A contribuição da simulação computacional para a análise sistêmica da reestruturação de layout e otimização de recursos na manufatura celular: estudo de caso em uma célula de uma empresa do ramo automotivo
}

\author{
João Pedro Marcante Soares \\ Engenheiro de Manufatura - John Deere Brasil \\ joaopedroms@hotmail.com \\ Fernando de Oliveira Lemos \\ Professor do Curso de Engenharia de Produção \\ Pontifícia Universidade Católica do Rio Grande do Sul \\ fernando.lemos@pucrs.br \\ César Luciano Klanovicz de Araújo \\ Consultor Produsul Consultoria \\ cesarlucianok@gmail.com \\ Peter Bent Hansen \\ Professor dos Cursos de Administração e de Engenharia de Produção \\ Pontifícia Universidade Católica do Rio Grande do Sul - PUCRS \\ peter.hansen@pucrs.br
}

\section{RESUMO}

A otimização dos recursos e a eliminação dos desperdícios são objetivos nos quais as empresas vêm investindo na busca da excelência operacional. Diante disso, cresce a necessidade da utilização de ferramentas que auxiliem no processo de tomada de decisão. Neste artigo apresenta-se um estudo de simulação computacional em uma empresa do ramo automotivo, com um ambiente organizacional focado em princípios do Sistema Toyota de Produção (STP). O estudo apresenta uma proposta de simulação computacional da reestruturação de um layout celular, a fim de avaliar a redução de estoques em processo, o aumento da produtividade, a redução do lead time e a adequação da mão-de-obra na célula de produção. A principal contribuição da utilização da simulação neste estudo consistiu no fato de que, além das melhorias esperadas no desempenho da célula de manufatura em função da aplicação dos conceitos do STP, como redução da ociosidade dos operadores, redução do WIP (work-in-process) e aumento da produtividade, outros impactos no desempenho da célula decorrentes da aplicação das mudanças, como dimensionamento dos buffers da linha e melhor distribuição das tarefas, difíceis de serem estudados de forma analítica, puderam ser observados e entendidos através da técnica de simulação, a qual permitiu uma compreensão sistêmica do objeto de estudo como um todo.

Palavras-chave: Sistema Toyota de Produção, Manufatura celular, Simulação computacional.

\begin{abstract}
The optimization of resources and the elimination of wastes are common scopes of companies pursuing operational excellence. This study uses simulation to evaluate how modifications in the layout affect the manufacturing efficiency of a company organized according to the Toyota Production System (TPS) principles. Modifications in the layout aimed at reducing the work-in-process, increasing productivity levels, reducing the lead time and idleness in the cell. The main contribution of the simulation use in this study consisted of the fact that, beyond the improvements expected in the performance of the manufacture cell obtained by the application of the concepts of the TPS, as idleness reduction, WIP (work-in-process) reduction and productivity increasing, other manufacture cell performance impacts due to the introduction of the changes, as better sizing of the line buffers and better tasks distribution, that were difficult to being studied at analytical form, were well observed and understood through the simulation technique, which allowed a systemic understanding of the cell operation as a whole.
\end{abstract}

Keywords: Toyota Production System, Cellular manufacturing, Computer simulation. 


\section{Introdução}

As constantes evoluções nos processos produtivos das empresas estão diretamente alinhadas com a necessidade de responder rapidamente às necessidades dos clientes. Em mercados cada vez mais globalizados, marcados pela velocidade da tecnologia da informação, as empresas competitivas são aquelas que respondem de forma rápida e flexível às necessidades dos clientes. Em paralelo, a escassez de recursos disponíveis para investimentos em melhorias dos processos produtivos, faz com que as empresas necessitem de ferramentas que auxiliem no direcionamento de suas tomadas de decisões e reduzam os riscos inerentes a estas.

A inserção das organizações em um contexto de racionalização e aprimoramento de recursos internos faz com que os princípios do Sistema Toyota de Produção (STP) surjam como uma alternativa para o aumento do potencial competitivo e busca pela excelência operacional. A aplicação destes princípios visa atender exigências do mercado por ciclos de produção e entrega mais curtos, maior variedade de produtos e respostas rápidas a variações de demandas.

O objetivo principal do STP é eliminar custos através da eliminação das perdas, ou seja, eliminar todas as condições que geram custos e não agregam valor ao produto. O modelo produtivo proposto pelo STP também se baseia em outros princípios que contribuem para melhorar o desempenho das empresas (SÁNCHEZ; PÉREZ, 2001): melhoria contínua; zero defeitos; produção e entrega Justin-Time (JIT); produção puxada; times multifuncionais; e descentralização de responsabilidades.

O sistema de produção JIT, um dos princípios base do STP, é composto de várias práticas gerenciais que permitem visibilidade, simplicidade e padronização de processos e operações. Uma das práticas intimamente relacionada ao sistema JIT é a manufatura celular, a qual converte todo ou parte do sistema produtivo em centros de trabalho ou células para produção de famílias de produtos ou componentes. $\mathrm{O}$ arranjo físico celular possibilita a diminuição do lead time de produção (tempo de atravessamento), a eliminação de transportes e/ou de movimentos desnecessários e a redução de work-inprocess (WIP) ou inventário em processo (OLORUNNIWO; UDO, 2002).

Vários estudos comprovam os benefícios obtidos com a utilização da manufatura celular. Com a implantação dos princípios do JIT e da manufatura celular em um processo produtivo, Wemmerlöv e Johnson (1997) reduziram em $41,6 \%$ o WIP, em $61,2 \%$ o tempo de atravessamento de produção e em 50,1\% o tempo de resposta a clientes. Miltenburg (2001), com a aplicação de um layout celular, obteve ganhos de $86 \%$ na redução de WIP, $75 \%$ na redução do tempo de ciclo das operações e um aumento de $76 \%$ na produtividade da empresa analisada. Lemos e Fogliatto (2003), através da implantação de um layout celular em uma empresa de pequeno porte, obtiveram redução de $13,7 \%$ no tempo de atravessamento, de $40 \%$ no WIP, de $22,2 \%$ no tempo de ciclo e aumento de $40 \%$ na produtividade do processo analisado. Souza Junior et al. (2009), através da implantação de um layout celular em uma empresa de tecnologia eletrônica, obteve a redução do espaço total utilizado pelas máquinas no processo estudado, a diminuição da quantidade de peças por lote e a definição do fluxo correto de matérias-primas no abastecimento do processo produtivo.

A aplicação da manufatura celular e os resultados obtidos nos estudos apresentados na literatura permitem afirmar que a implantação de células de manufatura acarreta diversos impactos simultâneos no funcionamento de um processo produtivo. A análise destes impactos exige uma metodologia estruturada e que permita uma visão sistêmica, rápida e de baixo custo dos efeitos e contribuições da manufatura celular em um processo produtivo.

Dentro deste cenário que demanda respostas rápidas e de baixo custo na tomada de decisão, a simulação computacional é cada vez mais aplicada nas empresas, na busca da otimização dos recursos e dos processos produtivos (HARREL et al., 2002).

Por sua vez, a simulação computacional objetiva a criação de um modelo matemático com o auxílio de um aplicativo computacional. Os modelos de simulação permitem avaliar o processo de produção e sua evolução ao longo do tempo, sendo uma técnica de grande utilidade em situações em que se verificam limitações de recursos e tempo. A utilização de simulação se justifica na avaliação da distribuição dos recursos disponíveis, alocando-os de forma adequada ao processo e garantindo níveis elevados de produção, bem como seu uso em sistemas caracterizados por elevado número de variáveis de decisão (LU; WHONG, 2006). Por exemplo, a simulação computacional apresenta resultados satisfatórios em estudos de melhoria de processos, auxiliando a tomada de decisão na identificação e tratamentos dos gargalos produtivos (bottlenecks), no balanceamento de mão-de-obra, na utilização de recursos e na redução de tempos de processo (WILLIANS; CELIK 1998). 
Considerando os aspectos abordados, o objetivo do presente trabalho é apresentar a aplicação de um método de trabalho para identificação dos vários ganhos simultâneos obtidos na reestruturação de um layout celular com o auxílio da simulação computacional. Para atingir o objetivo deste trabalho A proposta é analisar a situação inicial do layout da célula de produção de uma empresa do setor automotivo, propor mudanças no layout atual com base nos princípios do Sistema Toyota de Produção e analisar, de forma sistêmica, os resultados obtidos nas rodadas de simulação das mudanças propostas. Desta forma, a principal contribuição deste estudo está na proposta de um método estruturado para a análise sistêmica de mudanças em células de manufatura.

O trabalho foi operacionalizado através de um levantamento de tempos e movimentos das operações, capacidades de máquina, layout atual e entradas e saídas das peças no processo produtivo. O levantamento de dados foi realizado com o intuito de modelar matematicamente o processo produtivo, posteriormente analisado em um software de simulação, o que permitiu análises de várias mudanças para a reestruturação do layout celular e a melhoria de desempenho do sistema analisado.

Na seção 2 deste trabalho é apresentado o referencial teórico, onde são abordados os conceitos de manufatura celular e os benefícios da utilização da simulação computacional como ferramenta para tomada de decisão. $\mathrm{Na}$ seção 3 é apresentado o método de trabalho utilizado. Na seção 4 é apresentado o caso estudado, aplicando a sistemática proposta, e na seção 5 são analisados os resultados obtidos na simulação computacional. $\mathrm{Na}$ seção 6 são apresentadas as considerações finais sobre o trabalho realizado.

\section{Referencial Teórico}

Nesta seção os conceitos de manufatura celular e simulação computacional são abordados. Também são tratados os benefícios da utilização da manufatura celular para redução de perdas, e da simulação computacional como ferramenta para tomada de decisão em processos que exigem uma visão sistêmica.

\subsection{O Sistema Toyota de Produção e o layout celular}

O projeto de sistemas de manufatura deve atender às necessidades demandadas pelo mercado consumidor atual, como o aumento do número e da variedade de produtos, o que acarreta a necessidade de uma flexibilização da manufatura, acentuada pela redução do ciclo de vida dos produtos (SLACK; CHAMBERS; JOHNSTON, 2002). As empresas estão sendo forçadas a se enquadrarem neste contexto, visto que o mercado se apresenta cada vez mais exigente em relação à flexibilização dos processos produtivos. O Sistema Toyota de Produção (STP) oferece ferramentas e princípios que possibilitam a atuação em um cenário que exige esta flexibilidade.

O STP busca aumentar a eficiência da produção pela eliminação consistente e completa de desperdícios, ou seja, produzir mais com menos horas de trabalho, em um menor espaço físico, com menor inventário, menor quantidade de produtos defeituosos e maior variedade de produtos (OHNO, 1997; SÁNCHEZ; PÉREZ, 2001).

Um dos princípios básicos do Sistema Toyota de Produção é o Just-in-Time (JIT), o qual busca a excelência operacional, melhorando a produtividade, qualidade e flexibilidade nas empresas que o adotam em suas operações. Dentre os elementos do JIT que tornam isto possível, está a utilização da manufatura celular, que apoia-se na reorganização de layouts produtivos em células, na multifuncionalidade dos operadores e na padronização contínua das operações (LIKER; MEIER, 2007; MACKELPRANG; NAIR, 2010).

A manufatura celular é uma forma de organização do trabalho que representa uma alternativa aos outros tipos de layouts de processos, para, entre outras coisas, diminuir o lead time, reduzir estoques e melhorar qualidade (WEMMERLÖV; JOHNSON,1997).

O layout ou arranjo físico dos recursos internos de um processo produtivo tem papel fundamental no processo de flexibilização da manufatura das empresas. O layout é a forma como os recursos estão agrupados na área de manufatura e, dependendo da maneira como são distribuídos, garante que o fluxo das operações esteja bem definido, diminuindo a movimentação dos produtos no processo produtivo e racionalizando os tempos de passagem dos lotes de peças entre os postos de trabalho (SLACK; CHAMBERS; JOHNSTON, 2002).

Spencer e Guide (1995) e Flynn e Jacobs (2007) afirmam que, a partir da tecnologia de grupo para a definição de famílias de produtos, o layout celular reúne equipamentos e produtos afins em um espaço físico definido, proporcionando ganhos de escala típicos da utilização do layout em linha. Por outro lado, este tipo de layout apresenta flexibilidade para produzir itens de uma mesma família, proporcionando ganhos de flexibilidade típicos de um layout do tipo funcional. Os agrupamentos dos produtos em famílias são baseados na similaridade de geometria dos produtos, em função das operações dos equipamentos (do processo), ou de ambos (OLORUNNIWO; UDO, 2002). 
Os layouts celulares buscam a reorganização física de equipamentos, aproximando trabalhadores e máquinas, promovendo a multifuncionalidade e a flexibilidade da força de trabalho, evitando a geração de estoques entre operações intermediárias e problemas relacionados com a qualidade de lotes fabricados. Algumas vantagens na utilização do layout celular são a redução de custos com perdas por estoque, uma maior visibilidade dos problemas operacionais do processo produtivo e o melhor aproveitamento do potencial humano com a utilização de princípios de multifuncionalidade (SHINGO, 1996; GHINATO, 1999; SLACK; CHAMBERS; JOHNSTON, 2002; YAUCH; STEUDEL, 2002; FLYNN; JACOBS, 2007).
A Tabela 1 apresenta uma comparação entre os resultados de estudos de implantação de layout tipo celular. $\mathrm{O}$ estudo de Bischak (1996), por exemplo, obteve redução do work-in-process (WIP), aumento de produtividade e redução de mão-de-obra. Outros estudos apresentam a quantificação dos ganhos como, por exemplo, Lavasseur, Helms e Zink (1995), que afirmam que através da implantação do layout celular no processo produtivo da Steward Inc., obteve-se uma redução de $80 \%$ no WIP; de $86 \%$ no lead time ou tempo de atravessamento; de $27 \%$ na mão-de-obra utilizada; e de $56 \%$ no espaço físico necessário para a manufatura.

Tabela 1 - Resultados obtidos com a implantação do layout celular

\begin{tabular}{|c|c|c|c|c|c|c|c|c|}
\hline Resultado & $\begin{array}{c}\text { Wemmerlöv e } \\
\text { Hyer (1989) }\end{array}$ & $\begin{array}{l}\text { Lavasseur, } \\
\text { Helms e Zink } \\
\text { (1995) }\end{array}$ & $\begin{array}{c}\text { Bischak } \\
\text { (1996) }\end{array}$ & $\begin{array}{l}\text { Wemmerlöv } \\
\text { e Johnson } \\
\text { (1997) }\end{array}$ & $\begin{array}{l}\text { Miltenburg } \\
\text { (2001) }\end{array}$ & $\begin{array}{c}\text { Barroso } \\
\text { e Tubino } \\
(2004)\end{array}$ & $\begin{array}{c}\text { Barbosa } \\
\text { e Lima } \\
(2008)\end{array}$ & $\begin{array}{l}\text { Souza Junior } \\
\text { et al. (2009) }\end{array}$ \\
\hline $\begin{array}{l}\text { Redução de } \\
\text { WIP }\end{array}$ & $X$ & $X$ & $X$ & $\mathrm{X}$ & $X$ & $\mathrm{X}$ & & $\mathrm{X}$ \\
\hline $\begin{array}{l}\text { Redução do } \\
\text { lead time }\end{array}$ & $\mathrm{X}$ & $X$ & & $\mathrm{X}$ & & & $\mathrm{X}$ & $X$ \\
\hline $\begin{array}{l}\text { Redução do } \\
\text { espaço físico }\end{array}$ & & $X$ & & & & $\mathrm{X}$ & $X$ & $X$ \\
\hline $\begin{array}{l}\text { Aumento da } \\
\text { produtividade }\end{array}$ & & $X$ & $\mathrm{X}$ & & $X$ & $\mathrm{X}$ & & \\
\hline $\begin{array}{l}\text { Redução de } \\
\text { mão-de-obra }\end{array}$ & & $X$ & $\mathrm{X}$ & & & & $X$ & \\
\hline
\end{tabular}

Fonte: Elaborado pelos autores a partir das obras consultadas

Há diversas formas de células de manufatura como, por exemplo, layouts em forma de "S", "L" ou "U". Estas formas de layout são direcionadas para otimizar o fluxo de pessoas e componentes ou produtos, proporcionando a redução ou eliminação do tempo de espera em fila, do tempo de setup (preparação de equipamentos), do tempo de processamento e do tempo de movimentação (TUBINO, 1999). Dentre os diferentes tipos de layouts do tipo celular, Miltenburg (2001) caracteriza o layout tipo "U" como sendo um dos mais utilizados em empresas que adotam os princípios do STP.

O layout em "U” é caracterizado por manter próximas a entrada e a saída do fluxo de material e componentes e favorecer a utilização da mão-de-obra multifuncional, facilitando o trabalho de operadores polivalentes. Além disso, o layout tipo "U" pode ser mais facilmente adaptado a mudanças, como redução ou aumento do número de operadores alocados nos postos de trabalho (NAKADE; OHNO, 1999; GHINATO, 1999; ROTHER; HARRIS, 2002).
Os passos típicos para implementação de layouts tipo "U" em um ambiente de manufatura celular do tipo JIT são (SEKINE 1992 apud MILTENBURG, 2001): (i) construir um ambiente de multifuncionalidade operacional, promovendo a disciplina e o treinamento de operadores; (ii) organizar centros de trabalho em um arranjo no formato de "U"; (iii) estabelecer um tempo de ciclo de produção; (iv) otimizar tempos de preparação, ajuste e troca de ferramentas; ( $v$ ) estabelecer a produção puxada; (vi) introduzir métodos de automação; e (vii) introduzir gradualmente o sistema Kanban.

Rother e Harris (2002) propõem diretrizes que devem ser seguidas para a implantação de layout celular; são elas: (i) localizar máquinas e estações de trabalho próximas para minimizar a distância percorrida; (ii) eliminar espaços e locais onde o estoque de peças em processo possa ser acumulado; (iii) localizar o processo inicial e o final próximos um do outro; (iv) garantir a segurança e ergonomia da célula; e ( $v)$ remover os obstáculos do caminho percorrido pelo operador. 
Para Slack, Chambers e Johnston (2002), por sua vez, existem alguns princípios básicos que devem ser seguidos quando da implantação de um layout: (i) observar o espaço disponível; (ii) reduzir ao máximo transportes e movimentações; (iii) utilizar fluxos racionais de materiais e produtos; (iv) considerar as atividades de manutenção e controle de qualidade; (v) analisar condições de trabalho; e (vi) prever expansões futuras do processo produtivo.

Apesar dos benefícios potenciais possíveis de atingir com o uso de layout celular, uma questão que se coloca é como prever e avaliar os benefícios e impactos práticos e simultâneos que ocorrerão no caso da implantação de um layout deste tipo em uma instalação real. Neste ponto é que se torna relevante compreender o papel da simulação computacional.

\subsection{A simulação computacional e a previsão dos impactos das mudanças de layout}

A implantação e as alterações de layout podem implicar em elevado custo para as empresas. Etapas de estruturação e aprimoramento de layouts produtivos podem ser favorecidas pela utilização de simulação computacional. A simulação pode auxiliar em decisões sobre investimentos em layout fabril, através da análise do comportamento de diferentes alternativas de layout antes da implantação prática, evitando erros e custos desnecessários (ABDUELA; WAGNER, 2004; LEMOS; ANZANELLO; FOGLIATTO, 2006; MOREIRA, 2006).

Bertrand e Fransoo (2002) definem a simulação como uma técnica utilizada para solucionar problemas complexos. A simulação permite a observação de dados, gerados a partir de modelos computacionais que representam um sistema real (ou parte deste sistema), de forma que os experimentos sejam uma antevisão do que futuramente se realizará, auxiliando no processo de tomada de decisões (HOLLOCKS, 1992). A simulação computacional pode evitar decisões desacertadas que possam por em risco o funcionamento da empresa ou resultem em investimentos inadequados (KRAJEWSKI; RITZMAN, 2001).

Law e Kelton (2000) e Harrel et al. (2002) apresentam alguns benefícios da utilização da simulação computacional em condições similares as aqui estudadas: $(i)$ desenvolvimento de modelos adaptáveis à realidade, testando diferentes cenários e possibilidades de operação de um sistema, sem comprometimento de recursos; (ii) capacidade de simulação de sistemas complexos (dotados de elementos estocásticos), os quais não são adequadamente descritos por modelos matemáticos determinísticos; (iii) avaliação da distribuição dos recursos disponíveis, alocando-os de forma adequada ao processo e garantindo níveis elevados de produção; (iv) melhor controle sobre as condições experimentais em comparação com a aplicação prática no sistema real; (v) análise de longos períodos de tempo de uma operação em um tempo reduzido de simulação; e (vi) determinação de gargalos (bottlenecks) existentes no sistema e estudos relacionados à otimização do processo. Complementarmente, Montevechi, Duarte e Nilsson (2003) postulam que modelos de simulação permitem decisões facilitadas em sistemas caracterizados por elevado número de variáveis, além de reduzirem os custos de experimentação.

Na literatura há vários estudos de aplicação da simulação como ferramenta de análise de sistemas produtivos. Greasley (2004) apresenta um estudo que busca simular o sistema de manufatura de uma empresa com o objetivo de encontrar soluções otimizadas, alisando os níveis demandados de produção, balanceamento de linhas, tempos de ciclo e tempos de processamento de pedidos. Djamessi (2005) avaliou em seu trabalho os fatores que afetam a flexibilidade de células de manufatura.

Welgama e Mills (1995), através da realização de um estudo com o uso da simulação na fase de projeto de um sistema JIT, obtiveram ganhos no que tange à identificação de gargalos e implantação de operações que demandam operadores multifuncionais. Estes benefícios foram possíveis pela simulação da implantação de kanbans e de um layout celular no processo analisado. Selvaraj (2008) também avaliou a implantação do JIT e de sistemas kanban com a utilização da simulação computacional. Hachicha, Masmoudi e Haddar (2007) citaram em seu estudo vários trabalhos de outros autores, os quais atuaram na análise de projetos de células de manufatura, na comparação de diferentes layouts, na análise de produtividade e na análise de impactos de fatores operacionais no funcionamento de células de manufatura, de uma forma sistêmica focando diversas variáveis de forma simultânea.

Shafer e Charnes (1991), Kannan e Palocsay (1999) e Shambu e Suresh (2000) utilizaram a simulação para verificar as vantagens e desvantagens da utilização, em sistemas de produção, de layouts funcional e celular. Nestes estudos foram utilizados fatores para avaliação do desempenho como, por exemplo: (i) número de operações necessárias ao processamento de peças; (ii) tempos de processamento das peças; e (iii) tamanho de lote. Os autores concluíram que o sistema com layout celular possui vantagens significativas sobre o sistema com layout funcional. No caso destes estudos percebe-se um dos benefícios da simulação, qual seja a previsão e análise de diversos efeitos simultâneos gerados por mudanças em um processo produtivo, o que permite uma visão sistêmica destas mudanças, aspecto dificilmente obtido através de estudos analíticos convencionais.

Constata-se assim que a simulação computacional vem sendo utilizada com sucesso em estudos realizados nos 
sistemas de manufatura. Ela permite o estudo da operação através da análise de diversos parâmetros simultaneamente e pode ser utilizada como uma ferramenta para análises detalhadas de reestruturações de layouts (LAW; McCOMAS, 1999; ABDUELMULA; WAGNER, 2004).

Na modelagem e simulação de células de manufatura as características de projeto da célula em análise (tamanho da célula, layout, tipos de máquinas, equipamentos de armazenagem, transporte e manuseio de materiais e capacidade de carregamento de máquinas e estações de trabalho) devem ser consideradas, bem como fatores operacionais envolvendo disponibilidade de equipamentos, taxa de refugos e retrabalhos, tempos de setup, mix (composto) de produção, capacidade de estoques intermediários e tamanho do lote de produção. No processo de modelagem e simulação as interações entre operadores e máquinas e indicadores de desempenho também devem ser identificados (IRIZZARY; WILSON; TREVINO, 2001).

A performance da célula de manufatura pode ser medida de várias formas como, por exemplo: produtividade, níveis de WIP, tempo de atravessamento, média de trabalhos atrasados, média de trabalhos antecipados, tempo médio de trabalhos em espera, utilização de máquinas, utilização de operadores, custos de manuseio de materiais, custos de setup e custos de inventário. Estes indicadores de desempenho devem ser definidos já na modelagem matemática da célula de manufatura (IRIZZARY; WILSON; TREVINO, 2001; CHTOUROU; JERBI; MAALEJ, 2008), de forma que a simulação permita uma visualização simultânea e sistêmica das variáveis.

Vistas as questões relevantes vinculadas ao uso da simulação computacional, segue a abordagem do método de pesquisa utilizado.

\section{Método de Pesquisa Utilizado}

Para a obtenção do objetivo proposto neste trabalho uma sistemática para modelagem e simulação foi definida. O fluxograma com as etapas do método proposto é apresentado na Figura 1. Este método foi adaptado das etapas de desenvolvimento e implementação de modelos de simulação propostos por Law e Kelton (2000), Harrel et al. (2002) e Gavira (2003). As etapas do método de trabalho proposto são: (i) Formulação do problema e planejamento do estudo; (ii) Coleta de dados; (iii) Construção do modelo conceitual; (iii) Validação do modelo conceitual; (iv) Construção do modelo computacional; (v) Verificação e validação do modelo computacional; (vi) Definição do(s) experimento(s); (vii) Simulação do(s) Experimento(s); e (viii) Análise dos resultados.

Na primeira etapa é definido qual o problema existente no processo produtivo selecionado, com o intuito de auxiliar no planejamento do estudo e nas delimitações do modelo de simulação computacional. Na etapa inicial de um processo de modelagem e simulação computacional é necessária uma clara definição dos objetivos do trabalho de simulação, sob o risco da não obtenção de sucesso, no processo de simulação, pela falta de um escopo bem definido (BANKS, 1998). Esta etapa demanda um entendimento aprofundado do processo a ser simulado.

Na segunda etapa são coletados, no chão de fábrica, os dados necessários para a construção do modelo computacional. A qualidade dos dados de entrada é fundamental no desenvolvimento de um modelo computacional, para que o mesmo reflita da melhor forma possível a realidade analisada (VINCENT, 1998).

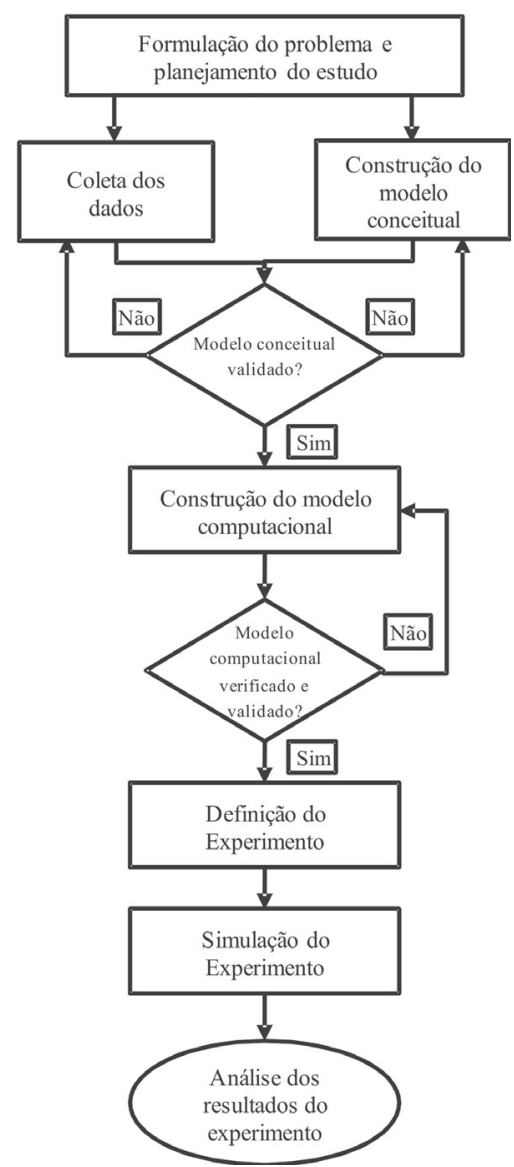

Figura 1 - Método proposto para modelagem e simulação Fonte: Adaptado de Law e Kelton (2000), Harrel et al. (2002) e Gavira (2003)

Na etapa de Construção do Modelo Conceitual desenvolve-se o modelo com base nas características da célula de manufatura que serão consideradas na modelagem computacional, bem como nos fatores operacionais, interações entre recursos e medidas de desempenho que serão avaliadas na simulação da célula. Após a coleta de dados e formulação do modelo conceitual deve-se validar o mesmo, definindo as características do sistema real que serão modeladas e verificando se o modelo está de acordo com o sistema real e com os propósitos da simulação computacional (SARGENT, 1999). 
Com o modelo conceitual validado pelos tomadores de decisão da empresa analisada, o modelo computacional é desenvolvido com o auxílio de um software de simulação. Há duas categorias de aplicativos computacionais para simulação de ambientes de manufatura (IRIZZARY; WILSON; TREVINO, 2001): (i) com linguagem de simulação para propósitos gerais; e (ii) com linguagem orientada para manufatura. Neste estudo foi utilizado o software ProModel, com linguagem orientada a modelagem e simulação de processos produtivos discretos, e que é indicado devido ao fato deste aplicativo computacional retratar o processo de montagem em uma manufatura celular, permitindo a avaliação da capacidade produtiva em cenários alternativos, bem como viabilizando análises em torno dos percentuais de utilização dos recursos produtivos no sistema.

O modelo computacional deve ser verificado e validado. Nesta etapa são realizadas rodadas de simulação do processo estudado, com o intuito de verificar e depois validar o modelo computacional. A validação do modelo é realizada através de um comparativo entre os resultados da simulação do modelo computacional e os parâmetros reais do processo produtivo estudado. É nesta etapa que são verificadas se as informações geradas, se as configurações e se os dados de entrada foram assimilados corretamente pelo modelo computacional (LAW, 2005).

A definição do experimento se baseia em mudanças no processo produtivo que objetivam a resolução dos problemas identificados na primeira etapa do método, na eliminação de perdas e na melhoria de desempenho do processo analisado. Após a definição do experimento, as mudanças definidas no mesmo são modeladas e o modelo computacional é utilizado para simular e analisar alterações e melhorias no processo produtivo. Os resultados obtidos com a simulação do experimento são analisados e as mudanças propostas são avaliadas em termos de viabilidade de implantação.

Na seção 4 é apresentada a aplicação do método proposto no processo de reestruturação de um layout celular em uma empresa do setor automotivo.

\section{Caso Estudado}

Este estudo aborda a análise do layout produtivo de uma célula de manufatura, com base nos conceitos e ferramentas do Sistema Toyota de Produção, experimentados através da simulação computacional. O estudo foi realizado na unidade de manufatura de usinagem de uma empresa do setor automotivo. A célula de manufatura estudada produz um item utilizado no sistema de transmissão de torque de veículos pesados, como caminhões, ônibus e caminhonetes.
Analisando esta célula de manufatura verificou-se um grande potencial de melhoria com a reestruturação do seu layout, pois, em estudos dos tempos do processamento da célula, foi identificada a oportunidade de melhoria no dimensionamento da mão-de-obra utilizada, na redução de estoque em processo e na redução do tempo de atravessamento das peças na célula. As subseções a seguir apresentam a aplicação das etapas do método proposto na seção 3 .

\subsection{Formulação do problema e planejamento do estudo}

Foi constatada, em observações preliminares, a ociosidade dos operadores e, conseqüentemente, uma oportunidade para otimizar o dimensionamento da mão-deobra na célula de manufatura. Alguns postos de trabalho geravam estoques intermediários, fazendo com que o WIP e o lead time de produção da célula aumentassem. A ociosidade dos operadores e o estoque de WIP foram os indicadores que determinaram a necessidade de reestruturação do layout atual da célula e a formulação do problema a ser resolvido neste estudo.

A partir da identificação dos problemas na célula de manufatura, definiu-se o objetivo da pesquisa como sendo a identificação e quantificação, com auxílio da simulação computacional, de alternativas para a reestruturação do layout atual da célula. Optou-se pela simulação computacional pelo fato dos procedimentos de simulação permitirem analisar, de maneira segura, as diversas repercussões, sobre o desempenho da célula, incluindo o redimensionamento da mão-de-obra e a redução da sua ociosidade.

Nesta etapa também foi realizado o planejamento do estudo, que abordou: a definição dos indicadores que seriam avaliados antes e após a simulação; e a definição dos dados a serem coletados para a modelagem matemática. Para análise dos resultados deste trabalho foram utilizados os seguintes indicadores de desempenho da célula de manufatura: número de operadores, capacidade produtiva, WIP, lead time de produção, ociosidade de operadores e ociosidade de máquinas.

Os dados coletados para a modelagem matemática de um processo produtivo podem variar de acordo com o tipo de processo, mas alguns dados podem ser considerados fundamentais para a modelagem como, por exemplo: número de máquinas e operadores; tempo-padrão de produção; tempo de setup; tempo de deslocamentos dos operadores; tempo de transporte de componentes; demanda de produção; e capacidade de produção. Os dados coletados no estudo da célula de produção analisada neste trabalho estão discriminados na próxima etapa do método proposto. 


\subsection{Coleta de dados e construção do modelo conceitual}

Nesta etapa foram coletados os dados de entrada para o desenvolvimento dos modelos conceitual e computacional. O primeiro passo na coleta de dados foi o entendimento do processo produtivo da célula de manufatura, apresentado na Figura 2. A célula analisada possuía doze máquinas ao longo do processo, dispostas em um layout tipo "U”. Destas doze máquinas, dois Tornos realizavam a operação de tornear perfil e duas Retíficas eram utilizadas na operação de retificar. Esta necessidade de duas máquinas em paralelo nestas duas operações se deve ao fato destas operações possuírem os maiores tempos de ciclo do processo, sendo a operação de torneamento dos perfis o gargalo da célula, ou seja, os dois tornos são os recursos restritivos da célula e limitam a capacidade produtiva de todo o processo.

Neste arranjo produtivo estavam alocados cinco operadores, realizando as atividades discriminadas na Figura 2 e posicionados conforme apresentado na Figura 3. Os operadores estão identificados na Figura 3 por letras e as máquinas por números.



Figura 2 - Fluxo do processo produtivo

Fonte: Elaborado pelos autores a partir de dados da empresa

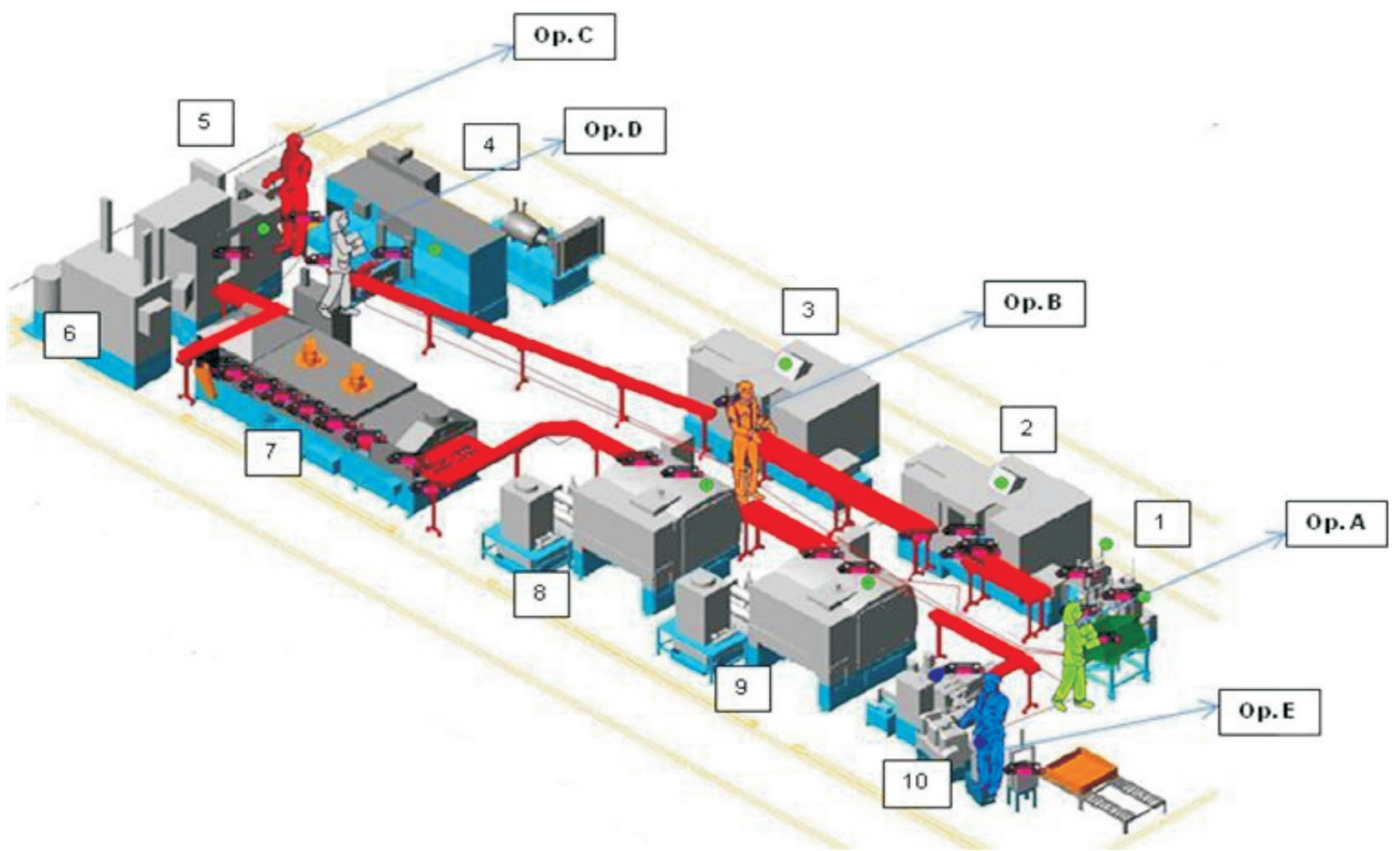

Figura 3 - Modelo do layout atual da célula

Fonte: Elaborado pelos autores a partir de dados da empresa 
O primeiro operador (Op. A) é responsável pelas 3 primeiras máquinas do processo, as duas Ponteadeiras (1) e o primeiro Torno (2). O segundo operador (Op. B) trabalha no segundo Torno (3) e na primeira Retifica (8), posicionada na frente do Torno (3). O terceiro operador (Op. C) opera a Roladora de entalhado (4) e a Lavadora (5). O quarto operador (Op. D) carrega na Indutora (6) as peças que saem da Lavadora (5) e depois carrega o Forno contínuo (7) com as peças que saem da Indutora (6). O quinto operador (Op. E) recebe pela esteira as peças vindas do Forno contínuo (7) e alimenta a Retífica (9), operada por ele. O operador (Op. E) também recebe as peças vindas já retificadas pelo operador (Op. 3) na Retífica (8). Na seqüência do processo o operador (Op. E) realiza as operações finais de laminar, fresar, olear e embalar na estação de trabalho (10).

A demanda média da célula é de 30.000 ponteiras fixas por mês. Considerando 25 dias disponíveis de produção por mês, a demanda diária é de 1.200 peças. Estudos de capacidade realizados pela empresa mostraram que a célula era capaz de atender esta demanda, havendo capacidade de sobra nas máquinas não gargalos. As máquinas mais exigidas no processo são os dois tornos (gargalos), os quais possuem os maiores tempos de ciclo, mas que também não eram utilizados na sua capacidade máxima.

A jornada diária de trabalho na célula era de 8 horas, em 3 turnos por dia, com uma hora de parada (descanso), ou seja, cada turno tinha 7 horas disponíveis para produção. Os turnos foram estruturados nos modelos conceitual e computacional, desenvolvidos conforme apresentado na Figura 4. O tempo efetivo de trabalho está representado em preto, as paradas para o intervalo estão representadas em cinza e em branco estão representas as horas não trabalhadas na semana.

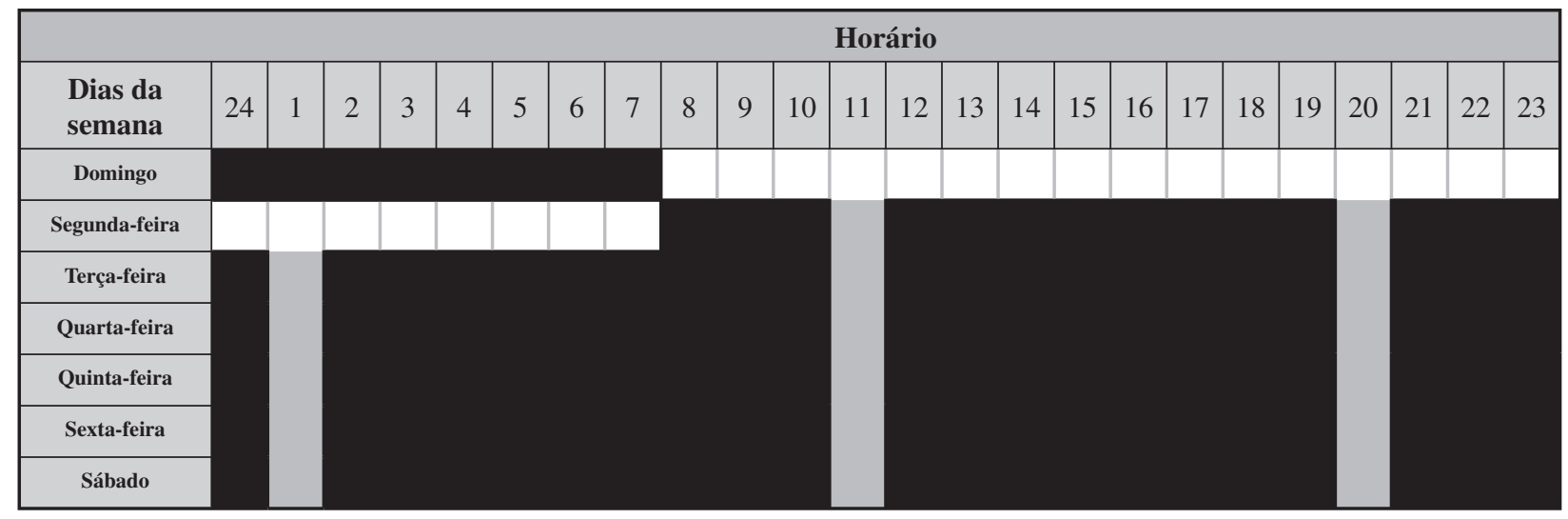

Figura 4 - Distribuição dos turnos de trabalho na célula

Fonte: Elaborado pelos autores a partir de dados da empresa

Os dados para o modelo foram obtidos através de um estudo de tempos e movimentos, no qual foi realizado o acompanhamento das tarefas de cada operador, desde a carga e descarga das máquinas até sua movimentação entre os postos de trabalho. As tarefas analisadas foram: carga e descarga de peças; inspeções; trocas de ferramentas; deslocamentos; tempos de operação das máquinas; e tempos dos setups e suas freqüências.

Foram realizadas 10 observações de cada operação e foi utilizado um aplicativo computacional estatístico (Stat Fit - módulo estatístico do software ProModel) para a análise da variabilidade dos tempos utilizados e definição das distribuições de probabilidade das variáveis cronometradas.

Uma análise do histórico dos tempos de parada para manutenção das máquinas também foi realizada. $\mathrm{O}$ tempo médio entre falhas (MTBF-mean time between failures) e o tempo médio para reparo (MTTR - mean time to repair) dos equipamentos foram calculados para inserção no modelo. As equações para os cálculos destes indicadores podem ser obtidas em Groover (2001).

Na estruturação do modelo conceitual foram considerados dois tipos de componentes. A empresa produz 3 tipos diferentes do item analisado; porém como dois tipos possuem os mesmos tempos de processamento, agrupou-se a demanda destes tipos a fim de simplificar a construção do modelo.

\subsection{Validação do modelo conceitual}

Modelar todos os detalhes do sistema pode tornar o processo de simulação complexo; desta forma se definem algumas restrições e/ou considerações para o sistema a fim de tornar o modelo mais simples, mas capaz de atender os objetivos definidos.

A construção deste modelo conceitual foi fundamentada nas seguintes considerações: (i) o modelo representará as atividades da célula de manufatura durante uma semana; (ii) os recursos humanos estão 
sempre disponíveis para realizar as tarefas; (iii) não há ocorrência de falta de peças (matéria-prima); (iv) algumas exceções de atividades de operadores e regras de movimentação de peças foram simplificadas, com o objetivo de reduzir a complexidade da construção e programação do modelo; e $(v)$ a taxa de qualidade foi considerada de $100 \%$.

As considerações adotadas e discriminadas nesta seção e na seção 4.2 foram apresentadas para a gerência da empresa, juntamente com o modelo idealizado (Figura 3 ) e os dados coletados. O modelo conceitual idealizado com base nestas considerações foi aprovado pela gerência da empresa, a qual considerou o modelo uma representação satisfatória do processo produtivo real existente.

\subsection{Construção do modelo computacional}

A partir da validação do modelo conceitual e coleta de dados foi desenvolvido o modelo computacional. O software utilizado para a construção foi o ProModel. Na etapa de construção deste modelo foram utilizados os seguintes elementos que compõem o aplicativo: $(i)$ Locais: estações de trabalho e seu respectivo posicionamento no modelo; (ii) Entidades: matérias-primas, componentes e produtos; (iii) Recursos: número de operadores; (iv) Redes de caminho: caminho a ser percorrido pelos operadores e produto no chão de fábrica; $(v)$ Chegadas: quantidade e frequiência dos componentes ingressantes no processo; e $(v)$ Processos: variáveis de tempo, distribuição de probabilidade e características do processo produtivo, entre outros.

A Figura 3 ilustra a representação do modelo computacional construído para a situação atual da célula de manufatura.

\section{Análise dos Resultados}

Esta seção aborda os resultados obtidos nas rodadas de simulação do modelo computacional. Desta forma parte-se dos resultados da verificação e validação iniciais do modelo para a posterior análise dos resultados dos experimentos realizados visando definir as futuras modificações a serem realizadas.

\subsection{Verificação e validação do modelo computacional}

O modelo foi analisado em relação às movimentações das entidades (que representam o produto em processamento) e verificou-se que as mesmas estavam seguindo o fluxo do processo real corretamente. As atividades dos operadores estavam de acordo com processo real, incluindo as caminhadas entre as máquinas, seqüência de acionamento das máquinas e frequiências de medições, representando a situação real da célula de manufatura.

Foram realizadas cinco rodadas de simulação, a fim de obter os resultados do modelo computacional. As rodadas realizadas geraram os resultados para a comparação com os dados reais de fábrica e validação do modelo programado. Como haviam dados gerados a partir de distribuições estatísticas, nem todos os eventos poderiam ocorrer somente com uma replicação, como, por exemplo, paradas de algumas máquinas para manutenção. Desta forma, se estipulou o valor de 5 replicações para permitir que todos os eventos fossem computados no modelo em análise. Araújo (2002) e Pinho et al. (2006) também utilizaram em seus modelos 5 replicações para suas rodadas produtivas e obtiveram resultados satisfatórios em termos de tendências de comportamento do sistema analisado. Para a validação do modelo foram utilizados os recursos gráficos de animação e os resultados gerados pelo software nas rodadas de simulação.

A demanda diária de referência foi de 1.200 peças, determinadas a partir da demanda mensal de 30.000 peças, considerando 25 dias de produção por mês. A capacidade efetiva do processo real é de 1.420 peças/ dia. O modelo construído reproduziu a capacidade diária da célula de manufatura e a ociosidade de capacidade que era observada na operação real da célula de manufatura. A capacidade produtiva obtida com o modelo computacional foi de 1.490 peças/dia.

Com os recursos de animação do software foram observados diversos parâmetros da célula, entre eles: (i) a ocupação dos operadores, que evidenciou a ociosidade identificada na operação real; (ii) o fluxo das entidades na linha; (iii) a sobra de capacidade da maioria das máquinas; e (iv) o comportamento da célula quando da quebra de algum equipamento, pois existe uma freqüência elevada de quebras das máquinas na célula de manufatura.

Como foi verificada uma proximidade (precisão aceitável) dos dados reais com os resultados obtidos, considerouse válido o modelo. O comparativo entre os parâmetros da operação real e os parâmetros gerados pelo modelo computacional é apresentado na Tabela 2. A diferença de valores obtidos com a simulação em relação à produção real da célula foi considerada aceitável pelos tomadores de decisão da empresa, visto que o modelo computacional simplificou o cenário simulado e não considerou algumas causas de variação na produção. Relembrando, o modelo computacional considerou que os recursos humanos estão sempre disponíveis para realizar as tarefas, que não há ocorrência de falta de peças (matéria-prima) e a taxa de qualidade foi considerada $100 \%$. 
Tabela 2 - Comparativo entre a operação real e o modelo da situação atual da célula de manufatura

\begin{tabular}{|c|c|c|}
\hline Condições Operacionais & Dados reais de fábrica & Dados obtidos pela simulação \\
\hline Capacidade diária média & 1.420 peças & 1.490 peças \\
\hline Capacidade semanal média & 9.100 peças & 9.270 peças \\
\hline WIP médio & 520 peças & 565 peças \\
\hline Lead time médio & $9 \mathrm{~h} 30 \mathrm{~min}$ & $10 \mathrm{~h} 27 \mathrm{~min}$ \\
\hline
\end{tabular}

Fonte: Elaborado pelos autores a partir dos resultados dos relatórios de simulação no ProModel

Com base no modelo representado na Figura 3, pôde-se avaliar as atividades dos operadores, ou seja, como foi utilizado o tempo gasto por eles para a realização das tarefas. A Tabela 3 apresenta a ocupação dos operadores durante sua rotina de trabalho. Analisando os dados da Tabela 3 pode-se concluir que a taxa de utilização dos operadores é baixa.

Tabela 3 - Dados de ocupação dos operadores no layout atual

\begin{tabular}{|c|c|c|c|}
\hline Operadores & Tempo em operação & Tempo em movimentação & Tempo ocioso \\
\hline Operador A & $35 \%$ & $4 \%$ & $61 \%$ \\
\hline Operador B & $25 \%$ & $6 \%$ & $69 \%$ \\
\hline Operador C & $45 \%$ & $10 \%$ & $45 \%$ \\
\hline Operador D & $16 \%$ & $83 \%$ & $85 \%$ \\
\hline Operador E & $15 \%$ & - & $8 \%$ \\
\hline
\end{tabular}

Fonte: Elaborado pelos autores a partir dos resultados dos relatórios de simulação no ProModel

A Tabela 4 apresenta o comportamento dos equipamentos durante uma semana de simulação. Na tabela estão representados os valores: do tempo efetivo de operação da máquina; do tempo de setup realizado; do tempo aguardando o operador para ser utilizada (tempo em espera da máquina); do tempo em que a máquina esteve bloqueada (aguardando o término de uma operação posterior a ela para poder operar); e do tempo em que esteve parada devido à manutenção.

Tabela 4 - Dados de ocupação das máquinas no layout atual

\begin{tabular}{|c|c|c|c|c|c|c|}
\hline Equipamentos & Operando & Ocioso & Em espera & Em setup & Bloqueado & Em manutenção \\
\hline Ponteadeira A (1) & $42 \%$ & $7 \%$ & $0 \%$ & $0 \%$ & $50 \%$ & $1 \%$ \\
\hline Ponteadeira B (1) & $26 \%$ & $8 \%$ & $9 \%$ & $0 \%$ & $57 \%$ & $0 \%$ \\
\hline Torno (2) & $97 \%$ & $2 \%$ & $0 \%$ & $0,5 \%$ & $0 \%$ & $0,5 \%$ \\
\hline Torno (3) & $95 \%$ & $0,5 \%$ & $3 \%$ & $0,5 \%$ & $0 \%$ & $1 \%$ \\
\hline $\begin{array}{l}\text { Roladora (4) } \\
\text { Indutora (6) } \\
\text { Retífica (8) } \\
\text { Retífica (9) } \\
\text { Laminadora (10) } \\
\text { Fresadora (10) }\end{array}$ & $\begin{array}{l}48 \% \\
89 \% \\
74 \% \\
72 \% \\
35 \% \\
50 \%\end{array}$ & $\begin{array}{c}13 \% \\
10 \% \\
24,5 \% \\
21 \% \\
50 \% \\
44,5 \%\end{array}$ & $\begin{array}{c}0 \% \\
0 \% \\
0,5 \% \\
5 \% \\
10 \% \\
5 \%\end{array}$ & $\begin{array}{c}1 \% \\
0 \% \\
1 \% \\
1 \% \\
1 \% \\
0,5 \%\end{array}$ & $\begin{array}{c}38 \% \\
0 \% \\
0 \% \\
0 \% \\
3 \% \\
0 \%\end{array}$ & $\begin{array}{l}0 \% \\
1 \% \\
0 \% \\
1 \% \\
1 \% \\
0 \%\end{array}$ \\
\hline
\end{tabular}

Fonte: Elaborado pelos autores a partir dos resultados dos relatórios de simulação no ProModel

Como citado na seção 4.2, ficaram evidenciados os gargalos da linha (os dois tornos), conforme quantificação apresentada na Tabela 4. Pode-se perceber pelos dados do modelo inicial, que a célula produziu acima da necessidade (Tabela 2), pois como haviam operadores dedicados às máquinas, os Tornos quase não ficaram ociosos, com utilização de $97 \%$ do Torno (2) e de $95 \%$ do Torno (3). Uma superprodução na célula de manufatura foi gerada e, conseqüentemente, um acúmulo de peças no estoque da fábrica. Pela análise da ocupação dos tornos verifica-se que a célula está perto do seu limite de capacidade, pois seus gargalos chegaram quase no limite de produção no modelo simulado. Assim, caso a empresa necessite de uma produção acima de 1.490 
peças/dia, a mesma pode ter de buscar alternativas para o aumento de capacidade, investindo em novas máquinas ou aumentando a capacidade dos seus gargalos.

\subsection{Definição do experimento}

Com base no modelo do layout atual, iniciaram-se as análises para formulação do experimento para atendimento do objetivo inicial do estudo. Foram estudadas propostas de alterações no layout produtivo e optouse por desenvolver mudanças no modelo inicial. As mudanças baseiam-se na aproximação das máquinas da célula entre si, com o objetivo de reduzir o tamanho das esteiras transportadoras, a quantidade de peças nas mesmas e a movimentação dos operadores.

Neste experimento também foi analisada a utilização de apenas 3 operadores para todas as operações da célula, ao invés dos 5 utilizados em cada turno de trabalho no layout atual. A utilização de 3 operadores foi definida pela empresa como o número ideal de operadores por célula para fins de análise, em função de suas experiências práticas anteriores (segundo informação da empresa). A alternativa foi modelada conforme apresentado na Figura 5.

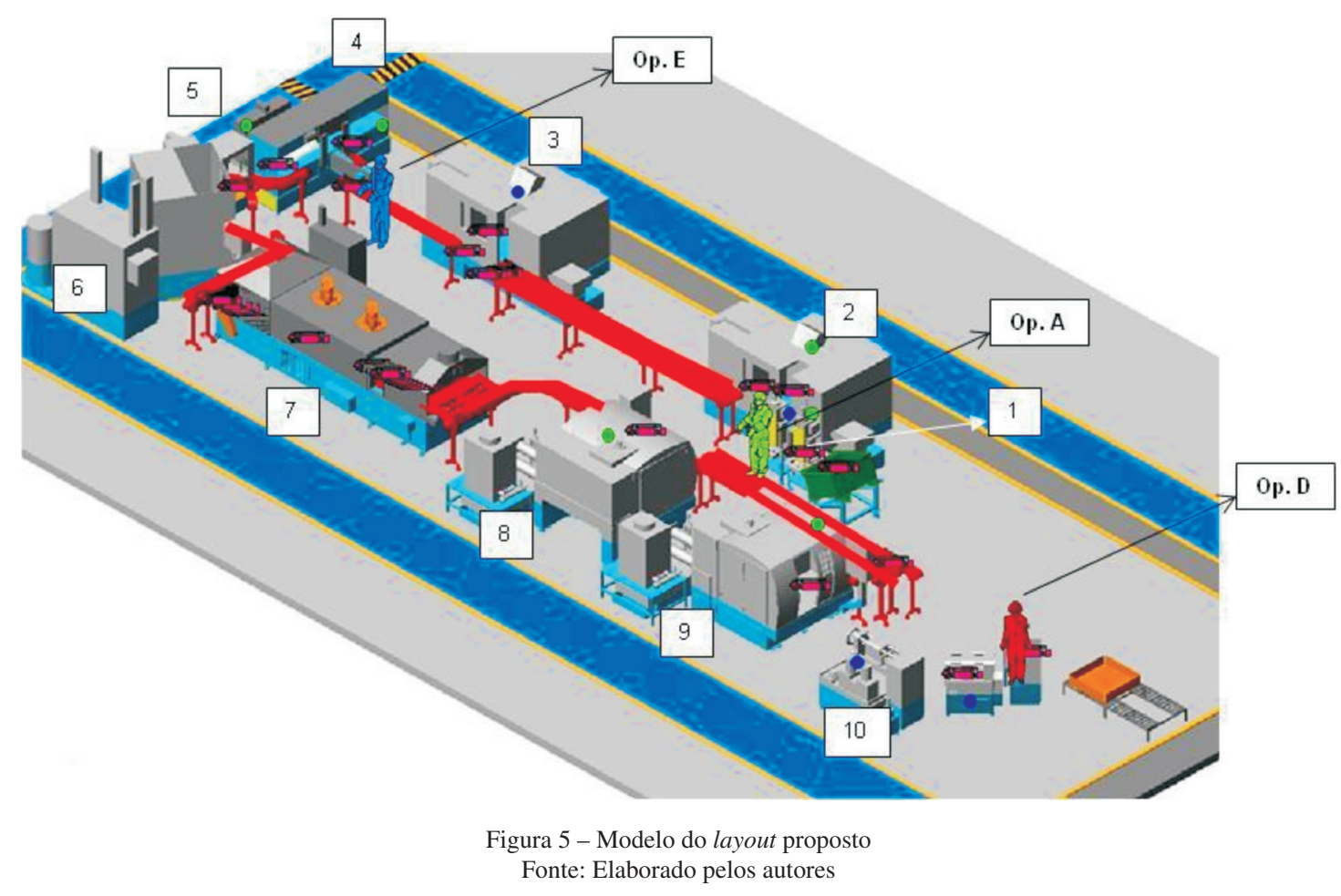

No modelo proposto distribuiu-se o trabalho para os 3 operadores. O primeiro operador (Op. A) passou a operar as duas Ponteadeiras (1) na entrada da linha, o primeiro Torno (2) e a primeira Retífica (8). O segundo operador (Op. E) ficou responsável pela operação do segundo Torno (3), a Roladora (4), a Lavadora automática (5) e a Indutora (6), que carregava as peças automaticamente para o Forno (7). O terceiro operador (Op. D) passou a operar a segunda Retífica (9) e as operações finais de laminar, fresar, olear e embalar (10).

Na entrada da linha de produção foi retirada a primeira esteira, pois não havia a necessidade de acumular peças antes dos Tornos (2) e (3) após a realização das operações de Ponteamento (1). Então o primeiro operador (Op. A) realizava a operação de pontear (1) e, aplicando fluxo peça a peça, logo após carregava o Torno (2). Enquanto uma peça era torneada, ele ponteava mais uma peça e a enviava para o segundo operador (Op. E) torneá-la no Torno (3). Os dois Tornos (2) e (3) foram aproximados da Roladora (4), diminuindo principalmente o deslocamento do segundo operador (Op. E) até o Torno (3). A Roladora (4) foi rotacionada em $90^{\circ}$ e a Indutora (6) em $45^{\circ}$ a fim de facilitar a movimentação do segundo operador (Op. E) e a aproximação do Torno (3) no layout. A Retífica (9) foi rotacionada em $90^{\circ}$, sendo posicionada de frente para a saída da linha, formando uma célula de produção para o terceiro operador (Op. D). Também foi eliminado o deslocamento para o acionamento da máquina e, com isso, pôde-se retirar uma esteira que ligava as Retíficas (8) e (9).

As capacidades das esteiras foram limitadas: em 10 peças na esteira antes da operação do Forno (7); em 50 peças na esteira de transporte do Forno (7) para a Retífica (8); e em 80 peças nas esteiras entre as Retíficas 
(8) e (9). Esta limitação de capacidade foi realizada para evitar acúmulos desnecessários, os quais ocorriam no modelo do layout atual e aumentavam o WIP e o lead time da célula.

No modelo do layout atual o Forno (7) foi construído como uma esteira contínua com limitação de 450 peças. Este local sempre estava disponível e durante as paradas ele continuava em operação, até que a última peça terminasse o ciclo. Por se tratar de um tratamento térmico o ciclo não podia ser interrompido, pois acarretaria o descarte das peças. No modelo do layout proposto a capacidade do Forno (7) foi reduzida para
350 peças a fim de reduzir o WIP e o lead time da célula de manufatura.

\subsection{Simulação do experimento e análise dos resultados}

A partir do modelo proposto foi simulado o funcionamento da célula e foram gerados dados de utilização dos operadores neste novo layout (Tabela 5). Para análise dos resultados do modelo do layout proposto foram realizadas 5 replicações (rodadas de simulação), tendose utilizado a mesma concepção utilizada na simulação do modelo atual (hoje existente) da célula.

Tabela 5 - Ocupação dos operadores no layout proposto

\begin{tabular}{|c|c|c|c|}
\hline Operadores & Tempo em operação & Tempo em movimentação & Tempo ocioso \\
\hline Operador A & $55 \%$ & $19 \%$ & $26 \%$ \\
\hline Operador E & $41 \%$ & $12 \%$ & $47 \%$ \\
\hline Operador D & $64 \%$ & $13 \%$ & $23 \%$ \\
\hline
\end{tabular}

Fonte: Elaborado pelos autores a partir dos resultados dos relatórios de simulação no ProModel

Na Tabela 6 são apresentados os dados de saída da simulação relacionados aos equipamentos da célula de produção. Como havia superprodução com a utilização dos 5 operadores notou-se que mesmo reduzindo a utilização dos tornos para $78 \%$ no Torno (2) e $83 \%$ no Torno (3), conforme a Tabela 6, a demanda semanal seria atendida. Com a limitação do número de peças nas esteiras e redução da mão-de-obra, os Tornos (2) e (3) acabaram ficando bloqueados, devido ao fato das esteiras ficarem cheias. Também foi identificado que as máquinas passaram a aguardar mais tempo para acionamento dos respectivos ciclos operacionais, o que resultou na redução de peças totais produzidas pela linha.

Tabela 6 - Dados de ocupação das máquinas no layout proposto

\begin{tabular}{|l|c|c|c|c|c|c|}
\hline Equipamentos & Operando & Ocioso & Em espera & Em setup & Bloqueado & Em manutenção \\
\hline Ponteadeira (1) & $34 \%$ & $21 \%$ & $5 \%$ & $0 \%$ & $39 \%$ & $1 \%$ \\
\hline Ponteadeira (1) & $26 \%$ & $4 \%$ & $19 \%$ & $0 \%$ & $51 \%$ & $0 \%$ \\
\hline Torno (2) & $78 \%$ & $1 \%$ & $15 \%$ & $0,5 \%$ & $5 \%$ & $0,5 \%$ \\
\hline Torno(3) & $83 \%$ & $1 \%$ & $4,5 \%$ & $0,5 \%$ & $10 \%$ & $1 \%$ \\
\hline Roladora (4) & $40 \%$ & $40 \%$ & $0 \%$ & $0,5 \%$ & $19 \%$ & $0,5 \%$ \\
Indutora (6) & $63 \%$ & $4 \%$ & $15 \%$ & $0 \%$ & $17 \%$ & $1 \%$ \\
Retifica (8) & $83 \%$ & $4 \%$ & $10 \%$ & $1 \%$ & $1 \%$ & $1 \%$ \\
Retifica (9) & $50 \%$ & $29 \%$ & $9 \%$ & $1 \%$ & $11 \%$ & $0 \%$ \\
Laminadora (10) & $33 \%$ & $40 \%$ & $21 \%$ & $1 \%$ & $4 \%$ & $0 \%$ \\
Fresadora (10) & $48 \%$ & $40 \%$ & $12 \%$ & $0 \%$ & $0 \%$ & $1 \%$ \\
\hline
\end{tabular}

Fonte: Elaborado pelos autores a partir dos resultados dos relatórios de simulação no ProModel

Analisando a Tabela 4, nota-se que as máquinas possuem mais tempo em operação no layout atual, pois os operadores estão dedicados a elas, porém as esteiras ficavam mais cheias, o que resultava em um maior WIP e um lead time maior. Como não havia limitação do número de peças nas esteiras, o WIP no modelo do layout atual (com 5 operadores) é crescente na linha de tempo (Figura 6) e, conseqüentemente, o seu lead time também aumenta (Figura 7). Devido ao fato de haver uma parada de um dia (entre os minutos 4.000 e 6.000 da linha de tempo - Figura 7) o WIP cai, porém volta a subir a partir da retomada da produção.

No gráfico de WIP do modelo proposto (com 3 operadores) apresentado na Figura 8, nota-se uma tendência de queda. Isto se deve à limitação do número de peças, não gerando superprodução entre as operações e acúmulo de peças dentro do sistema produtivo. A queda de WIP reflete no lead time do modelo proposto (Figura 9), o qual se manteve estável dentro de uma faixa entre 6 e 8 horas 
de tempo de atravessamento durante toda a semana, sem contar o tempo referente à parada do Domingo.

A célula do modelo proposto, entre os minutos 1.000 até 6.000 (Figura 8), apresentou um WIP estável devido ao Forno (7) permanecer sempre abastecido e pelo fato da taxa de saída de peças prontas manter-se constante. A partir dos minutos 6.000 até 7.000 ocorreu uma parada de um dia, e as peças, que permaneceram dentro do
Forno (7) durante esta parada, terminaram o seu ciclo operacional e foram abastecidas na parte final da linha (esteira para a primeira Retífica). Como o gargalo, conjunto de Tornos (2) e (3), é anterior ao Forno (7), quando a produção retorna na segunda-feira (equivalente ao tempo 7.000 minutos na Figura 8) a frequiência de saída de peças é superior à capacidade de entrada de peças (limitadas pelo gargalo) gerando uma queda no WIP.

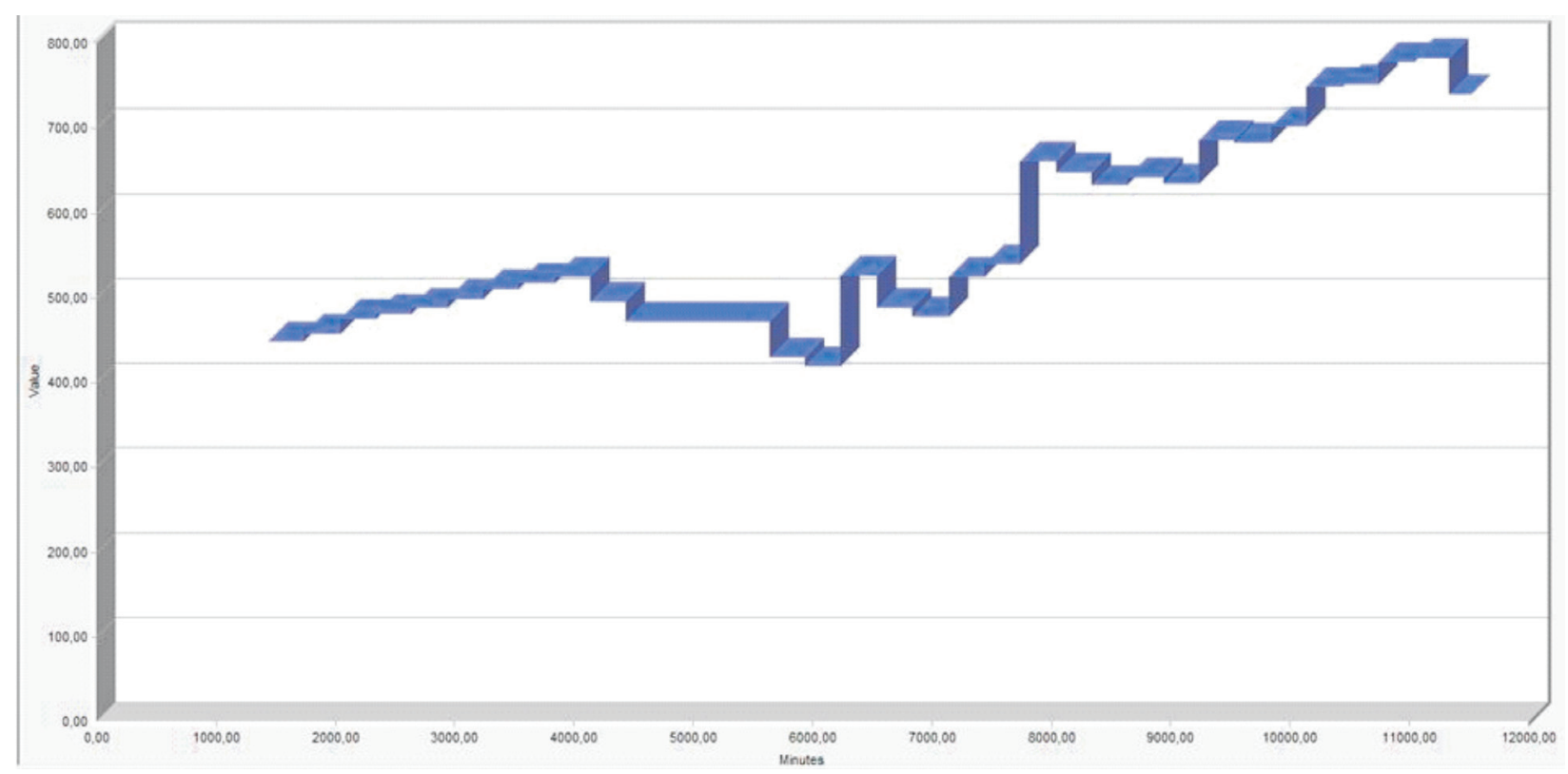

Figura 6 - Gráfico de controle do WIP no modelo do layout atual

Fonte: Elaborado pelos autores a partir dos resultados dos relatórios de simulação no ProModel

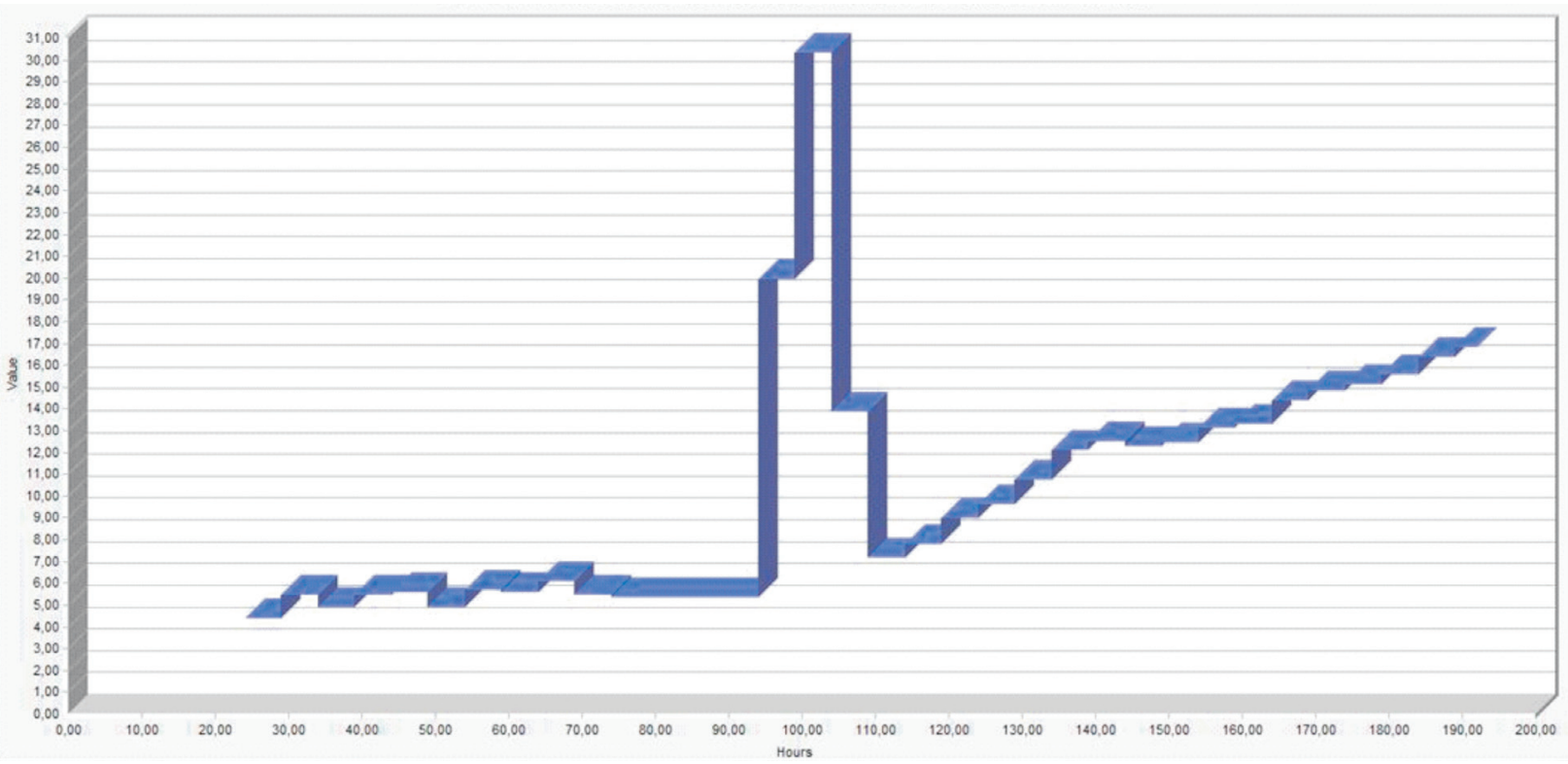

Figura 7 - Gráfico de controle do lead time no modelo do layout atual

Fonte: Elaborado pelos autores a partir dos resultados dos relatórios de simulação no ProModel 


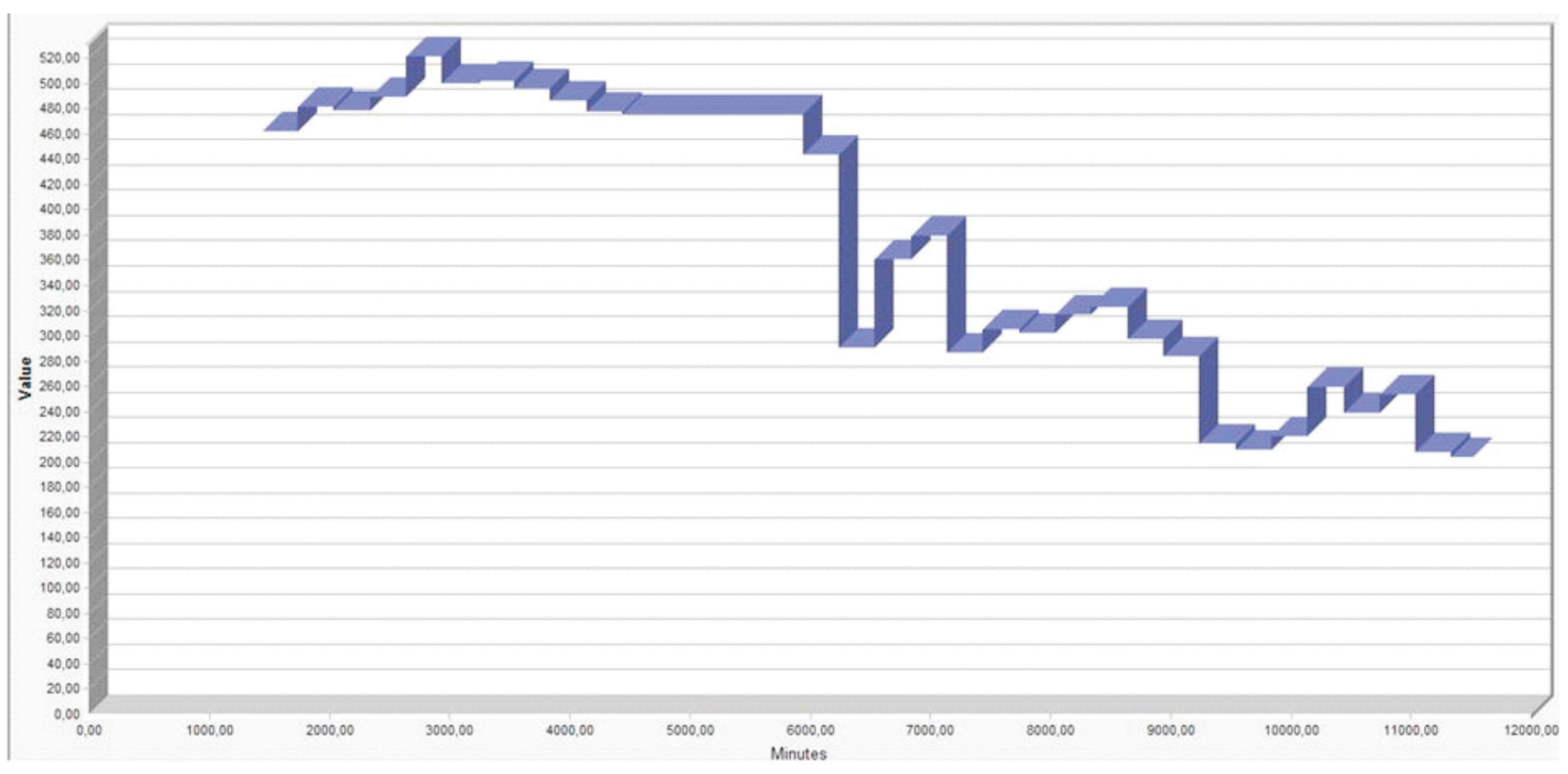

Figura 8 - Gráfico de controle do WIP no modelo do layout proposto

Fonte: Elaborado pelos autores a partir dos resultados dos relatórios de simulação no ProModel

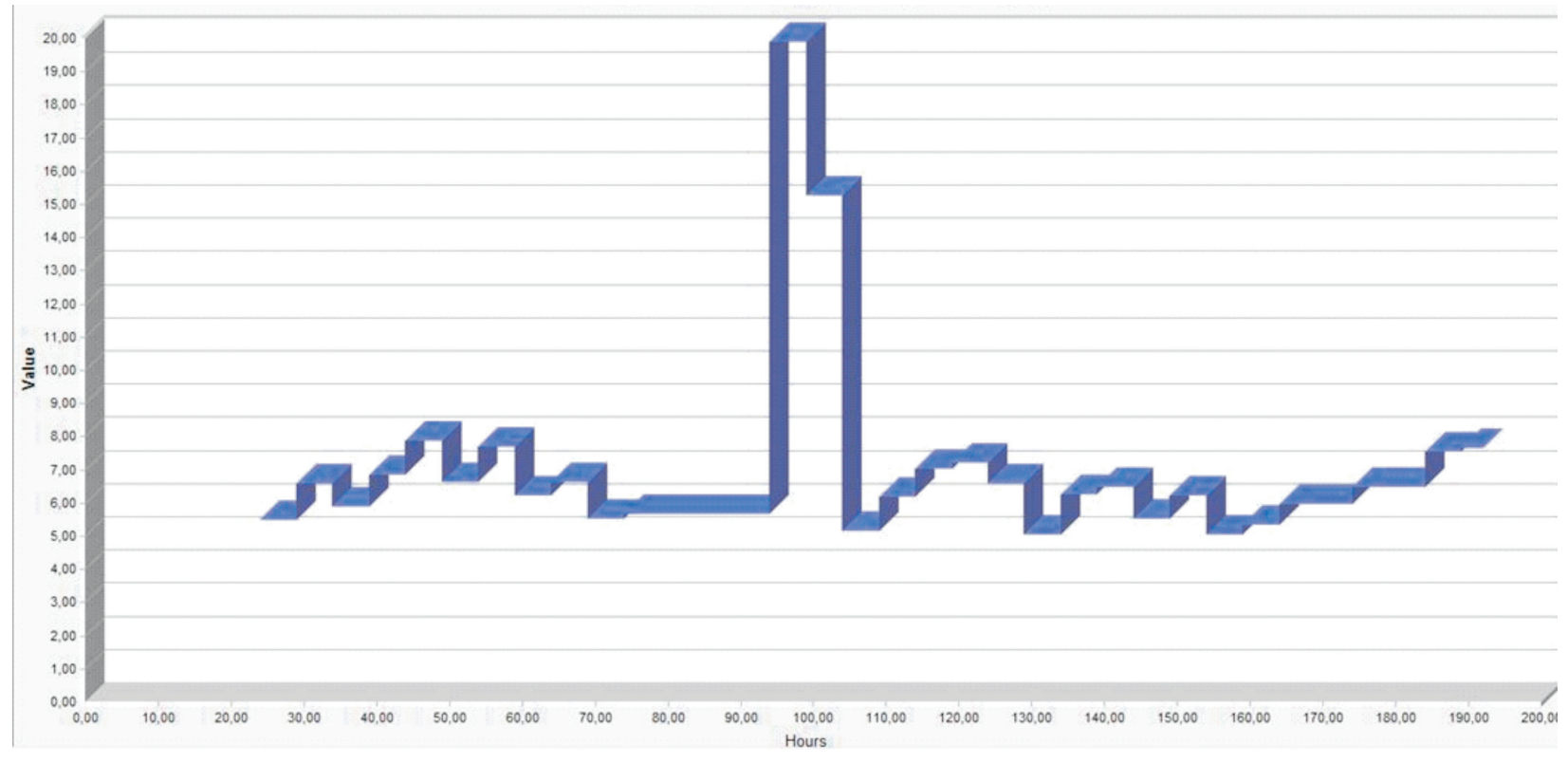

Figura 9 - Gráfico de controle do lead time no modelo do layout proposto

Fonte: Elaborado pelos autores a partir dos resultados dos relatórios de simulação no ProModel

Devido à racionalização das esteiras e do Forno (7), o WIP no modelo proposto obteve uma média de 375 peças durante a simulação, inferior ao modelo do layout atual, que possuía uma média de 564 peças, e o lead time diminuiu de $10 \mathrm{~h} 27 \mathrm{~min}$ para $6 \mathrm{~h} 31 \mathrm{~min}$ no modelo proposto.

Qualquer parada da linha por setup e/ou quebra para manutenção no modelo do layout atual, gerava acúmulo de peças nas esteiras, o que não ocorreu no modelo proposto, pois a produção foi limitada pela capacidade das esteiras. Quando houve limitação das mesmas, o maior percentual de peças dentro da célula ficou dentro dos fornos, como pode ser verificado pelo WIP apresentado na Figura 10. 

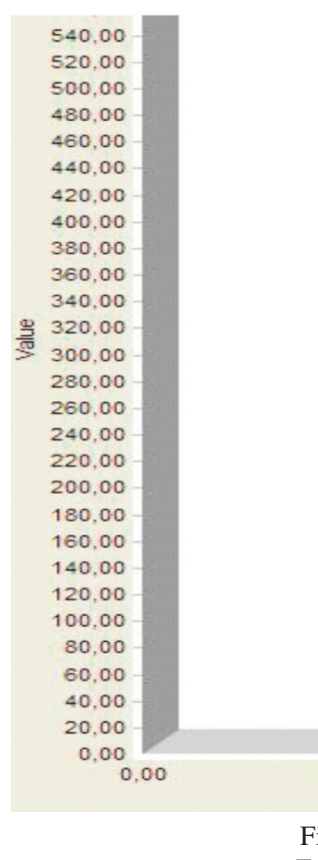

\section{An}

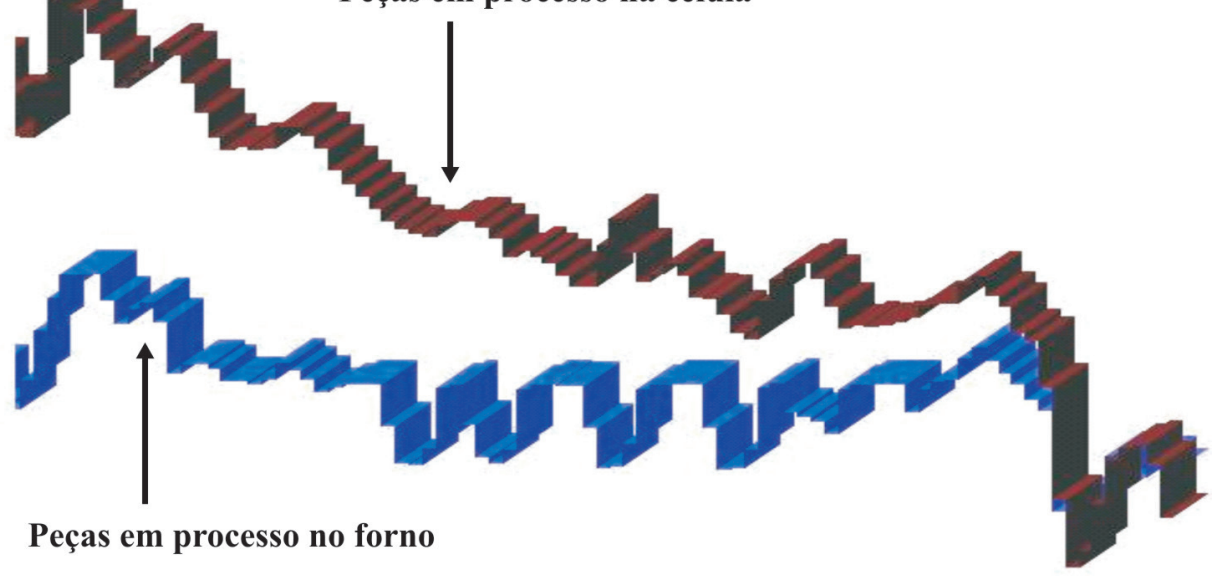

6000,00

7000,00

8000,00

9000,00

10000,00

11000,00 Minutes

Figura 10 - Comparativo entre quantidade de peças na célula e nos fornos no modelo proposto

Fonte: Elaborado pelos autores a partir dos resultados dos relatórios de simulação no ProModel

O modelo do layout proposto objetivou eliminar a grande ociosidade dos operadores nos seus respectivos postos de trabalho, alterando o layout atual da célula e implementando o alargamento das tarefas dos operadores. A simulação do layout atual apresentou um grande acúmulo de peças entre os postos de trabalho, reproduzindo o cenário real de produção da célula, o que motivou no experimento realizado a limitação da capacidade das esteiras, a retirada da primeira esteira e a retirada da esteira entre as Retíficas (8) e (9). Com a simulação do modelo proposto conseguiu-se distribuir as operações entre os 3 operadores propostos. Não foi preenchido por completo todo o tempo disponível de trabalho dos operadores, porém a taxa de utilização dos operadores aumentou consideravelmente (Tabela 5). A Tabela 7 apresenta um comparativo dos parâmetros operacionais antes e depois das alterações do layout da célula estudada.

Tabela 7 - Comparativo dos resultados da simulação dos modelos do layout atual e do layout proposto

\begin{tabular}{|c|c|c|}
\hline Variáveis de Saída (análise) & Resultados do modelo do layout atual & Resultados do modelo do layout proposto \\
\hline Capacidade diária média & 1.490 peças & 1.397 peças \\
\hline Capacidade semanal média & 9.270 peças & 8.876 peças \\
\hline WIP médio & 565 & 375 \\
\hline Lead Time médio & $10 \mathrm{~h} 27 \mathrm{~min}$ & $6 \mathrm{~h} 31 \mathrm{~min}$ \\
\hline Quantidade de Operadores para 3 turnos & 15 & 9 \\
\hline
\end{tabular}

Fonte: Elaborado pelos autores a partir dos resultados dos relatórios de simulação no ProModel

Houve uma redução de $34 \%$ no acúmulo de peças durante o processo. Com isso pode-se dizer que diminuiu o valor de capital imobilizado dentro da linha, disponibilizando mais recursos para outros investimentos da empresa. Como resultados gerais obtiveram-se: redução de $34 \%$ no WIP, redução de $39 \%$ no lead time e redução de $40 \%$ na necessidade de mão-de-obra na célula de manufatura. A capacidade de produção diminuiu, mas como a demanda diária é de 1.200 unidades na célula analisada pode-se afirmar que os ajustes de layout e de recursos humanos na célula garantem uma capacidade de produção diária 1.397 unidades, que atende a demanda de produção atual da empresa.
Aqui deve ser lembrado que um estudo analítico do problema abordado neste caso permitiria identificar, provavelmente, alguns benefícios potenciais da introdução dos conceitos de STP em um processo produtivo baseado em manufatura celular. No entanto, a simulação permite a visualização de todos os efeitos potenciais da mudança no layout, inclusive questões não previstas à princípio mas que se mostram relevantes no desempenho global do processo produtivo. Na Tabela 8 são apresentados os efeitos das mudanças simuladas, permitindo uma análise sistêmica de reestruturação da célula de manufatura. 
Tabela 8 - Comparativo dos efeitos esperados e verificados na reestruturação célula de manufatura

\begin{tabular}{|c|c|c|}
\hline Variáveis de Saída (análise) & Efeito esperado & Efeito verificado \\
\hline Capacidade produtiva (unidades/semana) & Aumento & Redução \\
\hline WIP médio (unidades) & Redução & Redução \\
\hline Lead Time médio (h) & Redução & Redução \\
\hline Ociosidade dos operadores (\%) & Redução & Redução \\
\hline Ociosidade das máquinas (\%) & Redução & Aumento \\
\hline
\end{tabular}

Fonte: Elaborado pelos autores

Os indicadores capacidade produtiva e ociosidade de máquinas não convergiram para o efeito esperado com as mudanças propostas na célula analisada. No layout proposto houve uma redução de capacidade produtiva devido ao fato da redução de mão-de-obra (de 5 para 3 operadores) ter acarretado em maior tempo de espera da máquinas para acionamento dos respectivos ciclos operacionais. Consequientemente, a ociosidade das máquinas aumentou em relação ao desempenho do layout atual, onde as máquinas possuem mais tempo em operação devido à disponibilidade de operadores dedicados a elas. Os outros efeitos esperados foram obtidos no experimento realizado: redução de WIP, redução de lead time e redução de ociosidade de operadores.

\section{Considerações Finais}

Este estudo teve como objetivo principal a aplicação de um método de trabalho para identificação dos vários ganhos simultâneos obtidos na reestruturação de um layout celular. A proposta para atingir o objetivo deste trabalho foi analisar a situação inicial do layout da célula de produção de uma empresa do setor automotivo e propor mudanças no layout atual, com auxílio da simulação computacional.

Analisando o funcionamento atual da célula de produção estudada verificou-se: que os operadores permaneciam ociosos durante parte das suas atividades; havia a possibilidade de redução de estoques em processo, devido ao acúmulo de peças; e havia a possibilidade de redução do tempo de atravessamento das peças na célula.

As mudanças propostas no layout e nos recursos humanos da célula estudada se basearam nos princípios de manufatura celular do STP e a análise das mudanças foi realizada com o auxílio da simulação computacional. Os princípios de manufatura celular, utilizados na simulação proposta neste trabalho, foram: $(i)$ a flexibilização do processo de produção, de forma a enriquecer o trabalho dos funcionários; (ii) a aproximação dos postos de trabalho e a aproximação dos materiais e ferramentas aos postos de trabalho; e (iii) o dimensionamento dos postos de trabalho de forma a proporcionar menor ociosidade dos operadores.
Neste estudo utilizou-se o software ProModel, o qual se mostrou capaz de auxiliar na modelagem matemática do processo e na visualização do funcionamento do sistema, possibilitando uma melhor percepção, para os operadores e gestores da empresa, de como a célula funcionaria em uma situação real, facilitando a aprovação das mudanças propostas. O caso apresentado comprovou que a ferramenta de simulação pode auxiliar no processo decisório de uma empresa.

A validade de um modelo é verificada quando existe uma proximidade dos resultados obtidos com a realidade, o que neste caso foi obtido, visto que o modelo proposto neste trabalho conseguiu reproduzir a situação real. $\mathrm{O}$ entendimento do processo produtivo foi um benefício direto do processo de modelagem e simulação computacional, mas também foi possível avaliar ganhos em indicadores importantes na gestão de processos produtivos.

Através dos resultados gerados pela simulação, obteve-se uma validação dos benefícios gerados pela implantação dos princípios de manufatura celular, bem como de sua importância na eliminação de perdas por transportes, movimentações, estoques e esperas. Com a simulação de mudanças no layout celular obteve-se uma redução de $34 \%$ no WIP, uma redução de $39 \%$ no lead time e uma redução de $40 \%$ na necessidade de mão-de-obra na célula de manufatura. Além disso, a capacidade de produção foi mantida em um nível que atende a demanda atual da empresa.

Deve-se destacar que a reorganização de um processo produtivo gera sempre um impacto para a cultura organizacional e, embora grandes melhorias de desempenho sejam possíveis, as empresas não devem inferir que melhorias imediatas serão alcançadas.

Uma contribuição da utilização da simulação neste estudo que se julga relevante, é a de que além das melhorias previstas no desempenho da célula de manufatura em função da aplicação dos conceitos do STP, como redução da ociosidade dos operadores, redução do WIP e aumento da produtividade, outros impactos no desempenho da célula decorrentes da aplicação 
das mudanças, como dimensionamento dos buffers da linha e balanceamento das tarefas entre os operadores, difíceis de serem estudados de forma analítica, puderam ser observados e entendidos através da simulação. A simulação computacional permitiu uma compreensão sistêmica dos elementos e variáveis envolvidas no objeto de estudo como um todo.

Em termos de limitações deste estudo, partiu-se do princípio de que o modelo não sofreu mudanças ou paradas pela influência de fenômenos externos, como o atraso de matérias-primas, falta de ferramentas para usinagem ou falta de operadores para o trabalho. Estes são problemas que ocorrem eventualmente em processos produtivos, porém não foram mensurados para inserção no modelo avaliado neste estudo, aspecto com o qual a empresa concordou.

Sugere-se para estudos futuros a criação de um modelo que simule um aumento de demanda na linha de produção, a fim de observar o comportamento das máquinas e operadores neste contexto. Notou-se também, pelo comportamento dos gráficos de WIP, que não houve uma repetição do comportamento ao longo do tempo, sugerindo que o processo não entrou em regime. Desta forma, devem ser realizados estudos para simular um período maior de tempo, com a inclusão das demais características do processo que não foram consideradas no presente trabalho como, por exemplo, falta de matéria-prima na célula, eventuais faltas de operadores disponíveis e variações de demanda não previstas.

\section{Referências}

ABDUELMULA, A.; WAGNER, C. Design and evaluation of lean manufacturing cells: a simulation model. In: IAMOT 2004, Washington, D.C., 2004, Anais... Washington, D.C.: International Association for Management of Technology, 2004.

ARAÚJO, R. M. Modelo de simulação para avaliação do fluxo de transporte rodoviário de sondas de perfuração terrestre de poços de petróleo. Florianópolis: UFSC, 2002. Dissertação (Mestrado em Engenharia de Produção), Departamento de Engenharia de Produção e Sistemas, Universidade Federal de Santa Catarina, 2002.

BANKS, J. Principles of simulation. In: BANKS, J. (ed.) Handbook of Simulation: Principles, Methodology, Advances, Applications and Practice. New York: John Wiley \& Sons, Inc., 1998, 870p.

BARBOSA, L. C.; LIMA, A. C. Aplicação do fluxo contínuo no processo de produção de estacas prémoldadas para fundação. In: XXVIII ENCONTRO NACIONAL DE ENGENHARIA DE PRODUÇÃO, Rio de Janeiro, 2008. Anais... Rio de Janeiro: Associação Brasileira de Engenharia de Produção, 2008.
BARROSO, U. I. B.; TUBINO, F. D. O layout celular na indústria moveleira de estofados. In: XXIV ENCONTRO NACIONAL DE ENGENHARIA DE PRODUÇÃO, Florianópolis, 2004. Anais... Rio de Janeiro: Associação Brasileira de Engenharia de Produção, 2004.

BERTRAND, J. W. M.; FRANSOO, J. C. Modelling and simulation: operations management research methodologies using quantitative modeling. International Journal of Operations \& Production Management, v. 22, n. 2, p. 241-264, Feb. 2002.

BISCHAK, D. P. Performance of a manufacturing module with moving workers. IIE Transactions, v. 28, n. 9, p. 723-733, Sep. 1996.

CHTOURO, H.; JERBI, A.; MAALEJ, A. Y. The cellular manufacturing paradox: a critical review of simulation studies. Journal of Manufacturing Technology Management, v. 19, n. 5, p. 591-606, Out. 2008.

DJASSEMI, M. A Simulation analysis of factors influencing the flexibility of cellular manufacturing. International Journal of Production Research, v. 43, n. 10, p. 2101-2111, May 2005.

FLYNN, B. B.; JACOBS, F. R. Applications and implementation: an experimental comparison of cellular (group technology) layout with process layout. Decision Sciences, v. 18, n. 4, p. 562-580, 2007.

GAVIRA, M. O. Simulação computacional como uma ferramenta de aquisição de conhecimento. São Carlos: USP, 2003. Dissertação (Mestrado em Engenharia de Produção), Escola de Engenharia, Universidade de São Carlos, 2003.

GHINATO, P. Autonomia e Multifuncionalidade no Trabalho: Elementos Fundamentais na Busca da Competitividade. In: GUIMARÃES, L. B. de M. Série Monográfica Ergonomia: Ergonomia de Processo. Cap. 4.1, v. 2, 2 ${ }^{\text {a }}$ Ed. Porto Alegre: PPGEP/UFRGS, 1999.

GREASLEY, A. The case for the organizational use of simulation. Journal of Manufacturing Technology Management, v. 15, n. 7, p. 560-566, Oct. 2004.

GROOVER, M. P. Automation, Production Systems, and Computer-Integrated Manufacturing. 2 ed. Upper Saddle River: Prentice Hall, 2001. 856p.

HACHICHA, W.; MASMOUDI, F.; HADDAR, M. An improvement of a cellular manufacturing system design using simulation analysis. Published in: International Journal of Simulation Modeling, v. 6, n. 4, p. 193-205, Dez. 2007. 
HARREL, C. R.; MOTT, J. R. A.; BATEMAN, R. E.; BOWDEN, R. G.; GOGG, T. J. Simulação: otimizando os sistemas. 2 ed. São Paulo: IMAM, 2002. 136p.

HOLLOCKS, B. A well-kept secret? Simulation in manufacturing industry reviewed. OR Insight, v. 5, n. 4, p. 12-17, Oct.-Dec.1992.

IRIZARRY, M. L. A.; WILSON, J. R.; TREVINO, J. A flexible simulation tool for manufacturing cell design, I: model structure, operation, and case Study. IIE Transactions, v. 33, n. 10, p. 827-836. 2001.

KANNAN, V. R.; PALOCSAY, S. W. Cellular versus process layouts: an analytic investigation of the impact of learning on shop performance. Omega, The International Journal of Management Science, v. 27, n.5, p. 583-592, Out. 1999.

KRAJEWSKI, L. J.; RITZMAN, L. P. Operations Management: strategy and analysis. 6 ed. New Jersey: Prentice Hall, 2001. 882p.

LAVASSEUR, G. A.; HELMS, M. M.; ZINK, A. A. Conversion from a functional to a cellular layout at Steward, inc. Production and Inventory Management Journal, v. 36, n. 3, p. 37-42, Ago.-Out. 1995.

LAW, A. M. How to build valid and credible simulation models. In: KUHL, M. E.; STEIGER, N. M.; ARMSTRONG, F. B.; JOINES, J. A. (eds.) Proceedings of the 2005 Winter Simulation Conference, Monterey: Winter Simulation Conference, p. 547-554, 2005.

LAW, A. M.; KELTON, W. D. Simulation Modeling and Analysis. $3^{\mathrm{a}}$ ed. Boston: McGrawHill, 2000. 760p.

LAW, A. M.; MCCOMAS, M. G. Simulation of manufacturing systems. In: FARRINGTON, P. A.; NEMBHARD, H. B.; STURROCK, D. T.; EVANS, G. W. (eds.) Proceedings of the 1999 Winter Simulation Conference, Phoenix: Winter Simulation Conference, p. 56-59, 1999.

LEMOS, F. O.; ANZANELLO, M. J.; FOGLIATTO, F. S. Simulação da capacidade teórica de uma linha de montagem tipo " $U$ " em uma empresa de pequeno porte. In: VI SEMANA DE ENGENHARIA DE PRODUÇÃO SUL AMERICANA, Porto Alegre, 2006. Anais... Porto Alegre: FEENG, 2006.

LEMOS, F. O.; FOGLIATTO, F. S. Implantação de layout tipo $U$ na linha de produção de uma empresa de pequeno porte. In: XXIII ENCONTRO NACIONAL DE ENGENHARIA DE PRODUÇÃO, Ouro Preto, 2003. Anais... Rio de Janeiro: Associação Brasileira de Engenharia de Produção, 2003.
LIKER, J. K.; MEIER, D. O Modelo Toyota: manual de aplicação. Porto Alegre: Bookman, 2007. 432p.

LU, M.; WHONG, L. Comparison of two simulation methodologies in modeling construction systems: Manufacturing-oriented PROMODEL vs. construction oriented SDESA. Automation in Construction. v. 16, n. 1, p. 86-95, Jan. 2007.

MACKELPRANG, A. W.; NAIR, A. Relationship between just-in-time manufacturing practices and performance: A meta-analytic investigation. Journal of Operations Management, v. 28, n. 4, p. 283-302, Jul. 2010.

MILTENBURG, J. U-shaped production lines: A review of theory and practice. International Journal of Production Economics, v. 70, n. 3, p. 201-214, Mar. 2001.

MONTEVECHI, J.; DUARTE, J.; NILSSON, G. $O$ uso da simulação para análise do layout de uma célula de manufatura. Revista Pesquisa e Desenvolvimento Engenharia de Produção, n. 1, p. 15-29, Dez. 2003.

MOREIRA, D. A. Administração da Produção e Operações. São Paulo: Thomson Learning, 2006. 619p.

NAKADE, K.; OHNO, K. An optimal worker allocation problem for $U$-shaped production line. International Journal of Production Economics. v. 60-61, n. 1, p. 353-358, Abr. 1999.

OHNO, T. Sistema Toyota de Produção: além da produção em larga escala. Porto Alegre: Bookman, 1997. 149 p.

OLORUNNIWO, F. O.; UDO, G. J. The impact of management and employees on cellular manufacturing implementation. International Journal of Production Economics. v. 76, n. 1, p. 27-38, Mar. 2002.

PINHO, A. F. de; LEAL, F.; MONTEVECHI, J. A. B.; MARINS, F. A. S.; MAPA, S. M. S.; RIBEIRO, M. J. C. Aumento da Produtividade em uma Linha de Montagem de Chassis Automotivos através da Simulação Computacional. In: XXVI ENCONTRO NACIONAL DE ENGENHARIA DE PRODUÇÃO, Fortaleza, 2006. Anais... Rio de Janeiro: Associação Brasileira de Engenharia de Produção, 2006.

ROTHER, M.; HARRIS, R. Criando Fluxo Contínuo: um guia de ação para gerentes, engenheiros e associados da produção. São Paulo: The Lean Enterprise Institute, 2002. 103p.

SÁNCHEZ, A. M.; PÉREZ, M. P. Lean indicators and manufacturing strategies. International Journal of 
Operations \& Production Management. v. 21, n. 11, p. 1433-1451, Nov. 2001.

SARGENT, R. G. Validation and Verification of Simulation Models. In: FARRINGTON, P. A.; NEMBHARD, H. B.; STURROCK, D. T.; EVANS, G. W. (eds.) Proceedings of the 1999 Winter Simulation Conference, Phoenix: Winter Simulation Conference, p. 121-130, 1999.

SELVARAJ, N. Simulation modeling and analysis of single line multi stage manufacturing system. Journal os Scientific \& Industrial Research, v. 67, n. 4, p. 277281, Abr. 2008.

SHAFER, S. M.; CHARNES, J. M. Cellular versus functional layouts under a variety of shop operating conditions. Decision Sciences, v. 24, n. 3, p. 665-681, Jun. 1991.

SHAMBU, G.; SURESH, N. Performance of hybrid cellular manufacturing systems: A computer simulation investigation. European Journal of Operation Research, v. 120 , n. 2, p. 436-458, Jan. 2000.

SHINGO, S. O Sistema Toyota de Produção: do ponto de vista da engenharia de produção. 2. ed. Porto Alegre: Bookman, 1996. 291p.

SLACK, N.; CHAMBERS, S.; JOHNSTON, R. Administração da Produção. 2. ed. São Paulo: Atlas, 2002. $747 \mathrm{p}$.

SOUZA JUNIOR, J. A.; ANDRADE, M. H. S.; SANTIAGO, K. G.; CARMO, B. B. T.; ALBERTIN, M. R. Desenvolvimento de layout celular utilizando a carta de relacionamentos em uma empresa de tecnologia eletrônica. In: XXIX ENCONTRO NACIONAL DE ENGENHARIA DE PRODUÇÃO, Salvador, 2009. Anais... Rio de Janeiro: Associação Brasileira de Engenharia de Produção, 2009.
SPENCER, M.; GUIDE, D. An exploration of the components of JIT. International Journal of Operations \& Production Management. v. 15, n. 5, p. 72-83, May. 1995.

TUBINO, D. F. Sistemas de Produção: a produtividade no chão-de-fábrica. Porto Alegre: Bookman, 1999. $134 \mathrm{p}$.

VINCENT, S. Input data analysis. In: BANKS, J. (ed.) Handbook of Simulation: Principles, Methodology, Advances, Applications and Practice. New York: John Wiley \& Sons, Inc., 1998, 870p.

WELGAMA, P. S.; MILLS, R. G. J. Use of simulation in the design of a JIT System. International Journal of Operations \& Production Management, v. 15, n. 9, p. 245-260, Sep. 1995.

WEMMERLÖV, U.; HYER, N. L. Cellular manufacturing in the U.S. industry: a survey of users. International Journal of Production Research. v. 27, n. 9, p. 15111530, Sep. 1989.

WEMMERLÖV, U.; JOHNSON, D. J. Cellular manufacturing at 46 user plants: implementation experiences and performance improvements. International Journal of Production Research. v. 35, n. 1, p. 29-49, Jan. 1997.

WILLIANS, E. J.; CELIK, H. Analysis of conveyor systems within automotive final assembly. In: MEDEIROS, D. J.; WATSON, E. F.; CARSON, J. S.; MANIVANNAN, M. S. (eds.) Proceedings of the 1998 Winter Simulation Conference, Washington: Winter Simulation Conference, p. 915-920, 1998

YAUCH, C. A.; STEUDEL, H. J. Cellular manufacturing for small businesses: key cultural factors that impact the conversion process. Journal of Operations Management. v. 20, n. 5, p. 593-617, Set. 2002.

Recebido em: 08/07/2011. Aceito em: 31/08/2011 